\title{
Capacity and power fade cycle-life model for plug-in hybrid electric vehicle lithium-ion battery cells containing blended spinel and layered-oxide positive electrodes
}

\author{
Andrea Cordoba-Arenass, ${ }^{\mathrm{a}, *}$, Simona Onori ${ }^{\mathrm{b}, * *}$, Yann Guezennec ${ }^{\mathrm{a}}$, Giorgio \\ Rizzoni $^{\mathrm{a}}$ \\ ${ }^{a}$ Center for Automotive Research and Department of Mechanical and Aerospace \\ Engineering, The Ohio State University, Columbus, OH, 43212, USA. \\ ${ }^{b}$ Department of Automotive Engineering, Clemson University, Greenville, 29607, USA
}

\begin{abstract}
This paper proposes and validates a semi-empirical cycle-life model for lithium-ion pouch cells containing blended spinel and layered-oxide positive electrodes. For the model development and validation experimental data obtained during an aging campaign is used. During the campaign the influence of charge sustaining/depleting operation, minimum state of charge (SOC), charging rate and temperature on the aging process is studied. The aging profiles, which are prescribed in power mode, are selected to be representative of realistic plug-in hybrid electric vehicle (PHEV) operation. The proposed model describes capacity fade and resistance increase as function of the influencing stress factors and battery charge throughput. Due to its simplicity but still good accuracy, the applications of the proposed aging model include the design of algorithms for battery state-of-health ( $\mathrm{SOH}$ ) moni-
\end{abstract}

\footnotetext{
* Corresponding author

${ }^{* *}$ Part of this research was conducted at the time she was Research Scientist at OSUCAR

Email addresses: cordoba-arenas.1@osu.edu (Andrea Cordoba-Arenas), sonori@clemson.edu (Simona Onori), guezennec.1@osu.edu (Yann Guezennec), rizzoni.1@osu.edu (Giorgio Rizzoni)
} 
toring and prognosis, PHEV optimal energy management including battery aging, and the study of aging propagation among battery cells in advanced energy storage systems.

Keywords: Lithium-ion battery, Capacity and power fade, NMC-LMO cathode, Semi-empirical model, cycle-life prognosis, PHEV cycling

\section{Introduction}

A crucial step towards the large-scale introduction of plug-in hybrid electric vehicles (PHEVs) in the market is to reduce the cost of their energy storage devices. Lithium-ion (Li-ion) batteries are the preferred energy storage technology in PHEVs due to their high energy and power density [1]. One of the goals of U.S Department of Energy (DOE) Vehicle Technologies Program for hybrid electric systems is to, by 2022, reduce the production cost of Li-ion batteries by nearly 75 percent from 2012 costs. Currently, battery cycle and calendar life represents one of the greatest uncertainties in the total life-cycle cost of advanced energy storage systems [2].

Generally, battery aging manifest itself in a reduction in the ability to store energy and deliver power, performance metrics correlated with loss in capacity and increase in internal resistance [3], [4]. Among the micromechanisms of Li-ion battery aging we cite active particle loss and metal sediment or SEI film accumulation. A review of today's knowledge on the mechanics of aging in Li-ion batteries can be found in [3], [5]. These physicalchemical mechanisms are enhanced by stress factors such as current severity (C-rate), operating temperature, state of charge (SOC), cycling rates, overcharge and over-discharge [3], [4]. The generation of long-term predictions of the evolution of capacity and/or resistance to predict when it will reach a predetermined threshold is referred as battery prognosis. Prognosis helps in 
making informed and timely life cycle management decisions, reducing warranty and maintenance costs while improving serviceability, availability and safety. Prognosis is possible when an aging model describing the evolution of aging over time/cycle is available.

Battery aging models can be classified as physics-based $[6,7,8,9,10$, $11,12,13]$ and semi-empirical models $[2,14]$. Due to its simplicity but still good accuracy, semi-empirical models have been used for on-line battery prognosis and state-of-health (SOH) estimation, and as part of other Battery Management System (BMS) tasks such as state-of-charge (SOC) estimation [4], [15]. Recently, semi-empirical models have been also used for PHEV optimal energy management including battery aging [16],[17] and for the study of aging propagation among cells in advanced battery systems [18]. Due to its potential applications, in this work, we choose to use the semiempirical approach for the aging model development.

During the past years, the concept of blended electrodes composed of several active materials is attracting attention. Blended cathodes promise the combination of benefits of different metal-oxides into a hybrid electrode to allow performance optimization [19], [20]. In particular, blended cathodes composed of layered-oxide positive electrodes such as $\mathrm{LiNi}_{1 / 3} \mathrm{Nm}_{1 / 3} \mathrm{Co}_{1 / 3} \mathrm{O}_{2}$ (NMC) and spinel oxide positive electrodes such as $\mathrm{LiMn}_{2} \mathrm{O}_{4}$ (LMO) have been considered as one of the most promising candidates for PHEV applications [21], [22]. NMC positive electrodes have high specific capacity, good thermal stability and good cycle life. However, they have poor performance at high rates [21]. On the other hand, LMO positive electrodes, have a high rate capability and a low-cost. However, they have a low cycle life [19]. NMC-LMO blended positive electrodes have been reported to have the benefits of the two metal-oxides [23], [21]. 
There have been substantial efforts to conduct experimental campaigns to understand the influence of different stress factors on battery aging for various cathode materials: $\mathrm{LiCoO}_{2}$ (LCO) [24, 25], LiNiO (LNO) [24], $\mathrm{Li}(\mathrm{Ni}, \mathrm{Co}) \mathrm{O}_{2}(\mathrm{NCO})[26,27,28,29], \mathrm{Li}(\mathrm{Ni}, \mathrm{Co}, \mathrm{Al}) \mathrm{O}_{2}$ (NCA) [30, 25, 31, 32], $\mathrm{LiFePO}_{4}$ (LFP) $[2,14,32], \mathrm{NMC}[33,34,35]$. The majority of these studies have also included efforts to develop semi-empirical aging models. The main stress factors investigated have been SOC, $\Delta$ SOC, C-rate, and Temperature. Recently, other PHEV related stress factors such as vehicle-to-grid services (V2G) [36], charging protocol [37] and SOC equalization [38] have been included.

Though NMC-LMO cathodes are considered an excellent candidate for PHEV applications, only few aging campaigns using this composite material have been published $[39,40,41,13]$. In [39] the effect of temperature and SOC on calendar-life and charge sustaining/depleting cycle-life are studied within a large aging campaign. In [40], cycle-life is studied under two scenarios. In the first, the effect of thermal cycling superimposed to charge sustaining/depleting operation is studied. In the second, the magnitude and randomness of constant power pulses is investigated. None of these studies have included the development of suitable aging models for BMS and prognostics schemes.

Despite the efforts reported in the literature, there is still the need to understand battery aging under more realistic PHEV operation. In particular, the development of accurate aging models able to assess and prognose the life of the most advanced li-ion cathode candidates under realistic automotive scenarios is critical. This paper proposes semi-empirical capacity and power fade aging models for Li-ion pouch cells with NMC-LMO positive electrodes based on PHEV aging cycles. During the aging campaign 
that provided data for the proposed model, the influence of charge sustaining/depleting operation, minimum SOC, charging rate and temperature on the aging process was studied [13].

This paper is organized as follows. Section 2 describes the design of experiments and the methodology used during the periodic state of health assessments. Section 3 presents the capacity fade experimental data and describes the development and validation of an aging model based on empirical relations of the stress factors with capacity fade. Section sumarizes and discusses the results in Section 3. Section 5 presents the resistance increase experimental data and describes the development and validation of a power fade model. Similarly, Section 6 sumarizes and discusses the results in Section 5. In Section 7, the conclusions are presented.

\section{Experimental Campaign}

The United States Advanced Battery Consortium (USABC) defines two operational modes for PHEVs, Charge-Depleting (CD) and Charge-Sustaining (CS) [1]. In CD mode the vehicle is allowed to operate in electric mode (i.e. the vehicle powered by the electric drive and onboard electric energy storage) and hybrid mode (i.e. the vehicle is powered by the electric drive and/or engine), with a net decrease in battery state-of-charge (SOC). Where the battery SOC is defined as the available capacity expressed as a percentage of rated capacity. In CS mode the vehicle is only allowed to operate in hybrid mode with a relatively constant battery SOC. Figure 1 shows an schematic of a typical SOC profile under PHEV cycle operation. During CD the battery is depleted starting from a battery $\mathrm{SOC}$ of $\mathrm{SOC}_{\max }$ and until reaching a predefined $\mathrm{SOC}_{m i n}$. During $\mathrm{CS}$ the battery SOC is kept within a window 
$\mathrm{UE}_{C S}$ with an average value of $\mathrm{SOC}_{\min }$ [1], see Figure 1 . We define $t_{C D}$ as the time spent in $\mathrm{CD}, t_{C S}$ as the time spent in $\mathrm{CS}$, and $\left(t_{C D}+t_{C S}\right)$ as the total operating time. The ratio of $\mathrm{CD}$ to the total operating time is then defined as the ratio of $t_{C D}$ to $\left(t_{C D}+t_{C S}\right)$,

$$
\text { Ratio }=\left(t_{C D}:\left(t_{C D}+t_{C S}\right)\right)=\frac{t_{C D}}{t_{C D}+t_{C S}}
$$

which indicates the fraction of time spent in CD mode over the total operation time. Therefore, Ratio $=1$ corresponds to $\mathrm{CD}$ operation i.e. all the operating time is spent in CD. Ratio $=0$ corresponds to $\mathrm{CS}$ operation, i.e all the operating time is spent in CS. Ratios such that $0<$ Ratio $<1$ correspond to mixed operation i.e. the total operating time is divided between CD and CS. For example, the SOC profile shown in Figure 1 corresponds to mixed operation with a Ratio of $1 / 2$, i.e, half of the CD-CS operation time is spent in CD while the other half is spent in CS.

Battery charging is typically done through CC-CV protocol [37]. That is, a constant current (CC) is used until the battery voltage reaches a predetermined limit, followed by a constant voltage $(\mathrm{CV})$ until the current declines to a predetermined value. In this work we express the current in terms of

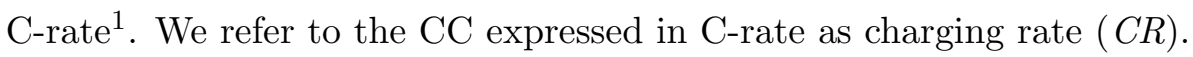

\subsection{Design of Experiments}

In order to understand battery aging under a more realistic vehicle cyclelife scenario; in this work, the following stress factors are defined for PHEV operation:

\footnotetext{
${ }^{1} \mathrm{~A}$ C-rate is a measure of the rate at which a battery is charge/discharged relative to its maximum capacity. Operationally, C-rate $=\frac{I(t)}{S_{0}}$, where $I(t)$ is battery input current and $S_{0}$ is the battery nominal capacity
} 
- Charging rate, $C R$

- Battery skin temperature, $T$

- $t_{C D}$ to $\left(t_{C D}+t_{C S}\right)$ Ratio

- Minimum state-of-charge, $\mathrm{SOC}_{\min }$

To understand the dependence of aging on the stress factors, the experimental data obtained during an aging campaign conducted on pouch cells with composite NMC-LMO positive electrode and carbon graphite negative electrode is used ${ }^{2}$. The design of experiments, previously reported in [13], is summarized in this section. Each cell has a nominal capacity of $15 A h$ at $1 \mathrm{C}$-rate and a nominal voltage of $3.75 \mathrm{~V}$. The battery cell cycling equipment consisted on 400 channels with a maximum capability of $8 \mathrm{~V}$ charge, 5V discharge and 400A, controlled using Labview.

The duty cycles used during the aging campaign are composed of the PHEV CD and CS micro-cycles defined by the USABC [1]. The duty cycles are prescribed in power mode, not current mode, preserving vehicle performance regardless of SOC and Temperature. In Figure 2 the power microcycles, which are scaled up to approximate a ten-mile CD range PHEV using a $\mathrm{BSF}^{3}$ of 94 , are shown.

Three sets of experiments were conducted:

- One set for CD operation, i.e. Ratio $=1$

\footnotetext{
${ }^{2}$ Aging campaign design by [13] and aged cells produced by the CAR Industrial Consortium/CARTech LLC.

${ }^{3}$ The Battery Size Factor (BSF) is defined as the minimum number of units (cells, modules or sub-batteries) of a given design required for a device to meet all U.S. Department of Energy Vehicle Technologies Program targets, including cycle life and calendar life [1].
} 
- One set for CS operation, i.e. Ratio $=0$

- One set for mixed operation, i.e. $0<$ Ratio $<1$

For the CD operation experiment, the power duty cycle consists of either five, six, or seven times a CD micro-cycle to cause an $\mathrm{SOC}_{\min }$ of approximately 45,35 , or $25 \%$, respectively. Then the cell is charged using a $C R$ of $\mathrm{C} / 3$, $3 \mathrm{C} / 2$, or $5 \mathrm{C}$ to a voltage of $4.15 \mathrm{~V}$, where a $\mathrm{CV}$ portion finishes the charge to $95 \%$ SOC and the entire cycle is repeated. A total of $9 \mathrm{CD}$ experiments, one for each case, were conducted at $30^{\circ} \mathrm{C}$.

For the CS experiment, the SOC is set by using the cell OCV vs. SOC curve to select the voltage corresponding to an $\mathrm{SOC}_{\min }$ of $45 \%, 35 \%$ or $25 \%$, respectively, then a CS micro cycle is repeated while keeping the voltage within a window of $10 \mathrm{mV}$ around the nominal setpoint. A total of $3 \mathrm{CS}$ experiments, one for each case, were conducted at $30^{\circ} \mathrm{C}$.

For the mixed operation experiment, the power duty cycle consists of seven times a CD micro-cycle to cause an $\mathrm{SOC}_{\min }$ of approximately $35 \%$, followed by CS micro-cycles repeated in Ratios of $1 / 2$ and $1 / 4$. Then the cell is charged using a $C R$ of $3 \mathrm{C} / 2$ following the protocol previously described and the entire cycle is repeated. Three experiments corresponding to a Ratio of $1 / 2$, each one conducted at $10^{\circ} \mathrm{C}, 30^{\circ} \mathrm{C}$ or $45^{\circ} \mathrm{C}$. One experiment corresponding to a ratio of $1 / 4$ was conducted at $30^{\circ} \mathrm{C}$. A total of 4 experiments were conducted.

Table 1 contains the summary of the experiments during the aging campaign. The campaign duration was up to 3 months of effective cycling test time. The resulting charge throughput expressed in ampere-hour throughput $(\mathrm{Ah})$ attained at the end of each experiment is shown in the last column of the table. 


\subsection{Cell Characterization}

Prior to and after the aging campaign, each cell was characterized using the following tests:

- Capacity test;

- Hybrid Power Pulse Characterization (HPPC) $)^{4}$. Test used to assess discharge and regen power capability

For the capacity test, the cell was fully charged and then discharge using a constant current of $1 \mathrm{C}(15 \mathrm{~A})$ to the lower voltage limit. The voltage limits used during the test were $V_{\max }=4.14 \mathrm{~V}$ and $V_{\min }=2.8 \mathrm{~V}$. The capacity was measured 3 times to established repeatability.

The HPPC current profile consists on ten-second duration, high constant current inputs with a 40-second open circuit in between. After the pulse sequence, the cell is immediately discharge with $10 \%$ DOD increments to traverse the SOC range and rested for $1 \mathrm{hr}$ before the pulse sequence is repeated [1]. This test sequence is repeated 9 times. Using a BSF of 94, the discharge and regen pulses correspond to a current of $5 \mathrm{C}(75 \mathrm{~A})$ and $3.75 \mathrm{C}$ (56.25A) respectively, and a $2 \mathrm{C}(30 \mathrm{~A})$ discharge current to traverse the SOC range.

During the life cycle aging campaign, cells were stopped periodically for assessment using the procedures previously described (approximately every two weeks). All the characterization tests were conducted at $30^{\circ} \mathrm{C}$. Figure 3 shows the voltage response during the capacity characterization tests for experiment \#16 in Table 1. The cell charge throughput expressed in kAh before each test is indicated in parenthesis.

\footnotetext{
${ }^{4}$ The HPPC test is conducted using a BSF of 94
} 


\section{Capacity Fade Model Development}

In a battery, the number of cycles is commonly expressed using the total ampere-hour throughput $[A h]$ in both charge and discharge, i.e. $A h=$

$\int_{0}^{t}|I(\tau)| d \tau$, where $I(t)$ is the input current to the battery [42]. The capacity fade [\%] of as a function of the battery charge throughput is then expressed as:

$$
S_{\text {loss }}(A h)=100 \cdot \frac{S_{0}-S(A h)}{S_{0}}
$$

where, $S_{0}$ is the cell nominal capacity and $S(A h)$ is the cell capacity after $A h>0$ charge throughput. It has been experimentally shown that the capacity fade in Li-ion batteries can be described using a power law relation with $A h[2]$, [14], [42]. Therefore, we adopt the following functional form for the capacity fade model,

$$
S_{\text {loss }}(A h)=f_{C}\left(S O C_{\text {min }}, \text { Ratio, } C R, T\right) \cdot A h^{z}
$$

where $f_{C}(\cdot)$ is a nonlinear function of the aging factors investigated during the aging campaign, and $z>0$. Capacity characterization data are used to quantify the capacity fade for the model development. The capacity characterization points obtained from experiment $i$ are fitted using the following expression:

$$
S_{l o s s, i}(A h)=f_{C, i} \cdot A h^{z_{i}}
$$

where, the coefficients $f_{C, i}$ and $z_{i}$ are the fitting parameters for experiment $i$. The optimal fitting coefficients are found using the Nonlinear Optimization Toolboox in Matlab. In particular, the nonlinear Levenberg-Marquardt algorithm is used to solve the data fitting problem in the least-squares sense. For the model development, a constant $z=0.48$, which corresponds to the 
average of the $z_{i}$ is used[14], [42]. The values of $f_{C, i}$ depend on the aging factors: Ratio, $\mathrm{SOC}_{\min }, C R$ and $T$.

In the following subsections, the effect of each aging factor on capacity fade is studied and described. A semi-empirical model based on empirical relations of the relevant aging factors with capacity loss is developed and validated. The model is developed by fitting the experimental capacity severity factor data points $f_{C, i}$ into empirical relationships. All the data fitting problems are solved in the least-square sense and using LevenbergMarquardt algorithm. The data obtained from experiment \#1 in Table 1 is discarded because it does not show consistency. This experiment is currently being repeated.

\subsection{Dependence of capacity fade on Charging Rate}

Lithium loss has been reported as one of the main mechanisms of capacity fade in Li-ion batteries during charging [37], [43]. It is estimated that more than $90 \%$ of the cyclable lithium loss during a CC-CV charging occurs during the $\mathrm{CV}$ portion, while the rest occurs during the $\mathrm{CC}$ portion [43]. During CV, higher values end-of-charge voltage (EOCV) lead to higher rates of capacity fade [43]. It has been also reported that metallic plating and subsequent lithium loss can also occur during the $\mathrm{CC}$ portion even during a normal CC-CV charging if the charging current rate exceeds a certain value [37]. The experimental data obtained suggested that there is no significant dependence of capacity fade on $C R$ under the charging conditions used during the experiments. This may be explained because the $C R \mathrm{~s}$ used are relatively low $(\mathrm{C} / 3,2 \mathrm{C} / 3$ and $5 \mathrm{C})$. Similarly, besides the use of the same CV $(4.15 \mathrm{~V})$ the EOCV reached while using $C R$ s of $\mathrm{C} / 3$ and $2 \mathrm{C} / 3$ were pretty close, $4.117 \mathrm{~V}$ and $4.116 \mathrm{~V}$ respectively. Moreover, while using 
the $C R$ of $5 \mathrm{C}$ ("fast charging"), the EOCV reached was $4.087 \mathrm{~V}$, a lower voltage than with the other two CRs, which may have compensated, if any, the effect of using a higher $C R$. Therefore, the $C R$ is not consider an stress factor for the development of the capacity fade model.

\subsection{Dependence of capacity fade on Temperature}

After eliminating the $C R$ from the stress factors, capacity fade may be affected by $\mathrm{SOC}_{\text {min }}$, Ratio and $T$. It has been reported by different authors that the dependence of capacity fade on temperature is a combination of different aging effects [2], [3],[32]. On one hand, at high temperatures, capacity fade follows an Arrhenius relation with operating temperature, a relation which describes the effect of temperature on the chemical side reactions responsible for battery aging such as SEI film accumulation [1],[3], [26], [28], [35]. For different cathode materials the Arrhenius relation describes the dependence of capacity fade on aging for temperatures greater that $15^{\circ} \mathrm{C}$. On the other hand, at low temperatures, capacity fade may follow an exponential decay with operating temperature, probably related to metallic lithium plating and subsequent electrolyte decomposition by metallic Li [3],[32]. Up to now, and to the best of our knowledge, this latter empirical relationship has not been fully understood and validated with experimental data. For this reason and since the experimental campaign conducted in this work was not intended to fully understand this later phenomenon, the experimental point corresponding to $10^{\circ} \mathrm{C}$ is not used for the aging model development. Therefore, the following expression for capacity loss is adopted:

$$
S_{\text {loss }}(A h)=f_{C}\left(S O C_{\text {min }}, \text { Ratio, } T\right) \cdot A h^{z}
$$


where, $f_{C}(\cdot)$ is the capacity severity factor function defined as $[2],[26]$ :

$$
f_{C}(\cdot)=a_{C}\left(S O C_{\text {min }}, \text { Ratio }\right) \cdot \exp \left(\frac{-E_{a_{C}}}{R_{g} T}\right)
$$

where, $E_{a_{C}}$ is the cell activation energy for the capacity fade process, $R_{g}$ is the is the universal gas constant, and $T$ is the cell absolute temperature.

The data from the temperature experiments along with the best curve fittings are shown in Figure 4(a). The experiments correspond to a Ratio of $1 / 2, \mathrm{SOC}_{\text {min }}=35 \%$ and a charging rate of $3 \mathrm{C} / 2$, at two different temperatures, $T_{1}=30^{\circ} \mathrm{C}$ and $T_{2}=45^{\circ} \mathrm{C}$ (Experiments \#14 and \#16 respectively, see Table 1). The data from these experiments along with Equation (6) is used to find the value of $E_{a_{C}}$. The following relationship is used:

$$
\ln \left[\frac{f_{C}\left(35 \%, 0.5, T_{1}\right)}{f_{C}\left(35 \%, 0.5, T_{2}\right)}\right]=\frac{-E_{a_{C}}}{R_{g}} \cdot\left(\frac{1}{T_{1}}-\frac{1}{T_{2}}\right)
$$

where, the values of $f_{C}\left(35 \%, 0.5, T_{1}\right)$ and $f_{C}\left(35 \%, 0.5, T_{2}\right)$ correspond to the optimal coefficients obtained from the data curve fitting and $l n$ is the natural logarithm function. The activation energy obtained for the capacity fade

process is $E_{a_{C}}=22406\left[\mathrm{Jmol}^{-1}\right]$. The rate of capacity fade increases while increasing the operating temperature for the temperature range under study.

\subsection{Dependence of capacity fade on Ratio}

The experiments conducted to study the influence of the Ratio on capacity loss correspond to experiments \#5, 11, 14 and 15 in Table 1 . The experiments were conducted at $\mathrm{SOC}_{\text {min }}=35 \%, \mathrm{~T}=30^{\circ} \mathrm{C}$, and ratios of $0,1 / 4,1 / 2$ and 1 , respectively. The experimental severity factor values are fitted to the following equation:

$$
a_{C}(35 \%, \text { Ratio })=\alpha_{1}+\beta \cdot(\text { Ratio })^{b}
$$


where, $\alpha_{1}=145, \beta=420$ and $b=0.34$ are the identified constants. Figure 5 shows the severity factor obtained form the experimental data best curve fittings, and the proposed empirical relationship for the dependence of capacity fade on the Ratio. The results of these experiments indicate that the rate of capacity fade increases while increasing the Ratio. The rate of capacity fade is the lowest at CS operating mode i.e. Ratio of 0 and increases rapidly while increasing the ratio, reaching the highest value during CD operation i.e. Ratio of 1 . Figure 4(b) shows the capacity characterization points obtained from experiments \#5, 11, 14 and 15 as markers, and the proposed empirical relationship, as solid curve. The results experiments \#2, 5 and 8, are used to validate the proposed model. Figure 6 shows the experimental data obtained from these experiments and the proposed empirical relationship. The experimental data points show good fitting with the proposed empirical relationship.

\subsection{Dependence of capacity fade on $S O C_{\min }$}

The experiments conducted to study the influence of $\mathrm{SOC}_{\min }$ on capacity fade correspond to experiments \#10,11, and 12 in Table 1 . The experiments were conducted at $T=30^{\circ} C$, with a Ratio of 0 , and $\mathrm{SOC}_{\min }$ of 45,35 and $25 \%$, respectively. The experimental capacity severity factor values are fitted to the following equation,

$$
a_{C}\left(S O C_{m i n}, 0\right)=\alpha_{2}+\gamma \cdot\left(S O C_{\min }-S O C_{0}\right)^{c}
$$

where $\alpha_{2}=137$ and $\gamma=9610$ are the identified constants for $S O C_{0}=0.25$ and $c=3$. Figure 7 shows the capacity severity factor points obtained from the experimental data best curve fittings, and the proposed empirical relationship for the dependence of capacity fade on $\mathrm{SOC}_{\text {min }}$. The results of these 
experiments indicate that the rate of capacity fade increases while increasing $\mathrm{SOC}_{\text {min }}$, this effect is more pronounced for $\mathrm{SOC}_{\text {min }}>35 \%$. Figure 4 (c) shows the capacity characterization points obtained from these experiments and the proposed empirical relationship.

\section{Capacity fade model}

Summarizing, capacity fade can be described by:

$$
S_{\text {loss }}(A h)=a_{C}\left(S O C_{m i n}, \text { Ratio }\right) \cdot \exp \left(\frac{-E_{a_{C}}}{R_{g} T}\right) \cdot A h^{z}
$$

where, $a_{C}(\cdot)$ is the capacity severity factor function given by:

$$
a_{C}(\cdot)=\alpha_{C}+\beta_{C} \cdot(\text { Ratio })^{b}+\gamma_{C} \cdot\left(S O C_{\min }-S O C_{0}\right)^{c}
$$

where, the dimensionless constant coefficients $\alpha_{C}, \beta_{C}, \gamma_{C}, b, c, z, \mathrm{SOC}_{0 C}$, and the dimensional constant coefficients $R_{u}$ and $E_{a_{C}}$ and are given by:

$$
\left\{\begin{array}{l}
\alpha_{C}=137 \\
\beta_{C}=420 \\
\gamma_{C}=9610 \\
b=0.34 \\
c=3 \\
z=0.48 \\
S O C_{0}=0.25 \\
E_{a_{C}}=22406 \quad\left[\mathrm{Jmol}^{-1}\right] \\
R_{g}=8.314 \quad\left[\mathrm{JK}^{-1} \mathrm{~mol}^{-1}\right]
\end{array}\right\}
$$

Figure 8 shows the fitted surface $a_{C}(\cdot)$ that describes the dependence of capacity fade on $\mathrm{SOC}_{\text {min }}$ and Ratio. The capacity characterization data points from experiments \#1,4,3,6 and 9 in Table 1 are used to validate the 
model. All conducted at $T=30^{\circ} \mathrm{C}$ with a Ratio of 1 . Experiments \#3,6 and 9 with $\mathrm{SOC}_{\min }=25 \%$, while experiments $\# 1$ and 4 with $\mathrm{SOC}_{\min }=45 \%$. Figure 9 shows the experimental points obtained from these experiments and the proposed model. The proposed empirical capacity fade model shows consistency with the experimental data points used for validation.

The goodness of fit for the capacity fade model is evaluated through the root mean square $(R M S)$ error defined as:

$$
R M S_{S}=\sqrt{\frac{\sum_{\substack{1<i<N \\ 1<m_{i}}}\left(\hat{S}_{\text {loss }, i}\left(A h_{j}\right)-S_{\text {loss }, i}\left(A h_{j}\right)\right)^{2}}{\sum_{\substack{1<i<N<m_{i} \\ 1<j<m_{i}}} 1}}
$$

where, $\hat{S}_{l o s s, i}\left(A h_{j}\right)$ is the estimated capacity loss for experiment $\# i$ at $A h_{j}$ charge throughput, $S_{l o s s, i}\left(A h_{j}\right)$ is the corresponding experimental point, $N$ is the total number of experiments, and $m_{i}$ is the total number of capacity assessment tests conducted during experiment \# $i$ (including initial, final and periodical state of health characterization tests). The root mean square obtained is $R M S_{S}=0.0047 \%$.

The capacity fade process follows a power law with the ampere-hour throughput. The power law factor, $z$, is very close to 0.5 , which indicates that one of the main mechanisms of capacity fade may be the growth of a solid electrolyte (SEI) layer, causing a square root of $A h$ shaped behavior [26], [35]. Usually SEI growth takes place mainly at the beginning of cycling and continues steadily with cycling [3]. Capacity fade follows Arrheniuslike kinetics, which indicates that it may be caused by thermally activated process. 


\section{Power Fade Model Development}

The internal resistance increase of a battery cell [\%] as a function of ampere-hour throughput can be expressed as:

$$
R_{\text {inc }}(A h)=100 \cdot \frac{R(A h)-R_{0}}{R_{0}}
$$

where, $R_{0}$ is the cell nominal internal resistance and $R(A h)$ is the cell internal resistance after $A h>0$ charge throughput. From observations of the obtained experimental data and aging studies reported in the literature the resistance increase in Li-ion batteries can be described using a linear relation with $A h$ [39]. Therefore, we adopt the following functional form for the resistance increase model:

$$
R_{\text {inc }}(A h)=f_{R}\left(S O C_{\text {min }}, \text { Ratio, } C R, T\right) \cdot A h
$$

where $f_{R}(\cdot)$ is a nonlinear function of the aging factors.

In a battery cell, the internal resistance is a function of the operational conditions: SOC, temperature and input current, charge/discharge [44]. There are different methods to calculate the internal resistance of a battery cell. For example, HPPC test, identification techniques using an equivalent circuit models of the battery cell, or using the input-output cell response and Ohm's law [1], [44]. The first two methods are not suitable for online applications, for this reason the third approach is selected to analyze the data. Using the experimental data, the battery cell internal resistance is calculated by observing the voltage response to every input current step increase/decrease and using Ohm's law as follows [45]:

$$
\hat{R}=\frac{\Delta V}{\Delta I}=\left|\frac{V_{\text {final }}-V_{\text {initial }}}{I_{\text {final }}-I_{\text {initial }}}\right|
$$


As illustration, a schematic of the input current and cell voltage response during the first 100 seconds of a CD micro-duty cycle are shown in Figure 10. In the figure, the initial currents and voltages used for the resistance calculations are shown as square markers; the final currents and voltages as triangle markers; and the input current and voltage response as solid curves.

In order to reduce noise and capture the actual trend in resistance increase, outlier removal and filtering methods were applied. Resistance values greater than 3 standard deviations from the average were removed to reduce resemblance. The cutoff criteria was chosen to remove false resistance values and not to remove data that did not fit the normal distribution. The removed values, which were not representative of the overall trend, typically constituted less than $1 \%$ of the total set. After the outlier removal, a moving average technique was chosen to capture the actual trend in resistance growth. The moving average window used has a length of 250 points.

Figure 11 shows the resistance data from experiment \#16 before and after the outlier removal and filtering. Similar resistance data processing results are obtained for the rest of the experiments. These simple calculations do not perfectly identify the actual value of the internal resistance; however, they provide a simple but still accurate approach to trace the overall trend of the resistance growth throughout the battery lifespan.

Resistance data processed as explained above are used to quantify the growth in internal resistance for the model development. The resistance points obtained from experiment $i$ are fitted using the following expression:

$$
R_{i n c, i}(A h)=f_{R, i} \cdot A h
$$

where, the coefficients $f_{R, i}$ is the fitting parameter. The fitting coefficients are found using a linear least squares approach. In the following subsections, 
the influence of the stress factors on the resistance growth is studied. Since the approach for the model development is similar to the one used for the capacity fade model, just the main highlights are presented in the next subsections.

\subsection{Dependence of resistance increase on Charging Rate}

In contrast to the capacity fade process, the experimental data suggest that there is dependence of resistance increase on the $C R$. For this reason, $C R$ is considered a stress factor for the model development in this case.

\subsection{Dependence of resistance increase on Temperature}

Following a similar approach as in Subsection 3.2 the following expression is used to describe the dependence of resistance increase on temperature:

$$
R_{\text {inc }}(A h)=a_{R}\left(S O C_{m i n}, \text { Ratio, } C R\right) \cdot \exp \left(\frac{-E_{a_{R}}}{R_{u} T}\right) \cdot A h
$$

where, $a_{R}(\cdot)$ is the resistance severity factor function which depend on $S O C_{\text {min }}$, Ratio, $C R ; E_{a_{R}}$ is the cell activation energy for the resistance increase process; $R_{u}$ is the is the universal gas constant; and $T$ is the cell absolute temperature. The activation energy obtained for the resistance growth

process is $E_{a_{R}}=51800 \quad\left[\mathrm{Jmol}^{-1}\right]$. Figure 12(a) shows the resistance characterization points obtained from experiments as markers, and the model, as solid curve. The rate of resistance growth increases while increasing the operating temperature for the temperature range under study.

\subsection{Dependence of resistance increase on Ratio}

The experiments conducted to study the influence of Ratio on resistance increase correspond to experiments \#5, 11, 14 and 15 in Table 1. These experiments were conducted at Ratios of $0,1 / 4,1 / 2$ and 1 , respectively. 
The experimental severity factor values obtained for Ratios of $1 / 4,1 / 2$ and 1 may be consider the same while the one obtained for Ratio $=0$ is significantly different from the others. This result suggest that the underlying influence of Ratio on resistance increase is the fact that during CS the battery is not fully charged (during CS the battery is operated during a narrow SOC window). Therefore, for the model development a "equivalent" $C R$ of zero is assigned for the CS operation. Therefore, the following equivalent $C R$ function is defined:

$$
C R_{e q}(\text { Ratio })= \begin{cases}0 & \text { Ratio }=0 \\ C R & \text { Ratio }>0\end{cases}
$$

\section{Resistance increase model}

Sumarazing the results from the model development, the resistance growth can be described by:

$$
R_{i n c}(A h)=a_{R}\left(S O C_{m i n}, \text { Ratio }, C R\right) \cdot \exp \left(\frac{-E_{a R}}{R_{u} T}\right) \cdot A h
$$

where, $a_{R}(\cdot)$ is the resistance severity factor function given by:

$$
\begin{array}{r}
a_{R}(\cdot)=\alpha_{R}+\beta_{R} \cdot\left(S O C_{\text {min }}-S O C_{0}\right)^{c_{R}} \\
+\gamma_{R} \cdot \exp \left[d \cdot\left(C R_{0}-C R_{e q}\right)+e \cdot\left(S O C_{\text {min }}-S O C_{0}\right)\right]
\end{array}
$$

where, $C R_{e q}$ is a function of Ratio given by:

$$
C R_{\text {eq }}(\text { Ratio })= \begin{cases}0 & \text { Ratio }=0 \\ C R & \text { Ratio }>0\end{cases}
$$


and, the dimensionless constant coefficients $\alpha_{R}, \beta_{R}, \gamma_{R}, c_{R}, d, e, S O C_{0}$ and the dimensional constant coefficients $R_{u}$ and $E_{a_{R}}$ and are given by:

$$
\left\{\begin{array}{l}
\alpha_{R}=3.2053 e+05 \\
\beta_{R}=1.3674 e+09 \\
\gamma_{R}=3.6342 e+03 \\
c_{R}=5.45 \\
d=0.9179 \\
e=1.8277 \\
S O C_{0}=0.25 \\
C R_{0}=5 \\
E_{a R}=51800 \quad\left[\mathrm{Jmol}^{-1}\right] \\
R_{g}=8.314 \quad\left[\mathrm{JK}^{-1} \mathrm{~mol}^{-1}\right]
\end{array}\right\}
$$

Figure 13 shows the resistance severity factor surface $a_{R}(\cdot)$ that describes the dependence of resistance growth on $\mathrm{SOC}_{\min }$ and $C R_{e q}$. The results indicate that the rate in resistance growth increases while increasing $\mathrm{SOC}_{\min }$, and the rate in resistance growth increases while decreasing $C R_{e q}$. Figures $12(\mathrm{~b}, \mathrm{c}, \mathrm{d})$ show the resistance characterization points obtained from experiments \#2 to 12 and \#14,16 along with the proposed model.

Since the model objective in this case is to capture the trend on the resistance growth and not to predict the instantaneous value of the battery internal resistance; the goodness of fit for the model is evaluated through $(R M S)$ error defined over the resistance severity factor as:

$$
R M S_{R}=\sqrt{\frac{\sum_{1<i<N}\left(\hat{f}_{R, i}-f_{R, i}\right)^{2}}{N}}
$$

where, $\hat{f}_{R, i}$ is the estimated severity factor for experiment $\# i, f_{R, i}$ is their corresponding experimental severity factor point, and $N$ is the total number 
of experiments. The root mean square obtained is $R M S_{R}=2.0495 e-05$.

The resistance increase process follows a linear relationship with $A h$. Additionally, the power loss process follows an Arrhenius-like kinetics, which indicates that the resistance growth may be caused by a thermally activated process.

\section{Conclusions}

This paper presented the results of a experimental campaign conducted on Li-ion pouch cells with NMC-LMO positive electrodes. During the campaign the influence of charge sustaining/depleting operation, minimum SOC, charging rate and temperature on the aging process is studied. The results show that capacity fade and resistance increase are influenced by Ratio, $\mathrm{SOC}_{\min }, C R$ and temperature. Using a non-linear curve fitting technique, a semi-empirical aging model which describes the capacity fade and resistance increase as a function of the influencing stress factors and the ampere-hour throughput was proposed based on the experimental data. The proposed aging model is indented to be used for predicting battery cycle-life under realistic PHEV operation. For its simplicity but still good accuracy, the model can be used for the design and sizing of PHEV energy storage systems; for the design and implementation of algorithms for battery state-of-health assessment and end-of-life prediction (prognosis); as part of PHEV optimal energy management schemes including battery aging, among others. The aging model may be also used for more research-oriented purposes such as the study the propagation of aging among cells in battery systems. 


\section{ACKNOWLEDGEMENTS}

The authors wish to thank the CAR Industrial Consortium ${ }^{5} /$ CARTech LLC for producing the aged cells. This material is based upon work supported by the National Science Foundation under Grant Number NSF1301238 and the Department of Energy under Award Number DE-PI0000012.

\section{DISCLAIMER}

Any opinions, findings, and conclusions or recommendations expressed in this material are those of the author(s) and do not necessarily reflect the views of the National Science Foundation. This report was prepared as an account of work sponsored by an agency of the United States Government. Neither the United States Government nor any agency thereof, nor any of their employees, makes any warranty, express or implied, or assumes any legal liability or responsibility for the accuracy, completeness, or usefulness of any information, apparatus, product, or process disclosed, or represents that its use would not infringe privately owned rights. Reference herein to any specific commercial product, process, or service by trade name, trademark, manufacturer, or otherwise does not necessarily constitute or imply its endorsement, recommendation, or favoring by the United States Government or any agency thereof. The views and opinions of authors expressed herein do not necessarily state or reflect those of the United States Government or any agency thereof.

\footnotetext{
${ }^{5}$ The CAR Industrial Research Consortium receives funding through annual membership fees paid by: GM, Ford, Cummins, Chrysler, Honda, Oshkosh Truck, Bosch, Eaton, Caterpillar, Lubrizol, Case-New Holland, Renault, Samsung, Tenneco, TRC Inc.
} 


\section{References}

[1] Anonymous, United States Department of Energy Battery Test Manual for Plug-In Hybrid Electric Vehicles, inl/ext-07-12536, rev 2 Edition (December 2010).

[2] J. Wang, P. Liu, J. Hicks-Garner, E. Sherman, S. Soukiazian, M. Verbrugge, H. Tataria, J. Musser, P. Finamore, Cycle-life model for graphite-lifepo4 cells, Journal of Power Sources 196 (8) (2011) 39423948 .

[3] J. Vetter, P. Novák, M. Wagner, C. Veit, K.-C. Möller, J. Besenhard, M. Winter, M. Wohlfahrt-Mehrens, C. Vogler, A. Hammouche, Ageing mechanisms in lithium-ion batteries, Journal of Power Sources 147 (1-2) (2005) $269-281$.

[4] S. Onori, P. Spagnol, V. Marano, Y. Guezennec, G. Rizzoni, A new life estimation method for lithium-ion batteries in plug-in hybrid electric vehicles applications, International Journal of Power Electronics 4, Issue 4 (2012) 302-319.

[5] M. Wohlfahrt-Mehrens, C. Vogler, J. Garche, Aging mechanisms of lithium cathode materials, Journal of Power Sources 127 (1-2) (2004) $58-64$.

[6] C. Y. Wang, W. B. Gu, B. Y. Liaw, Micromacroscopic coupled modeling of batteries and fuel cells: I. model development, Journal of The Electrochemical Society 145 (10) (1998) 3407-3417.

[7] R. Spotnitz, Simulation of capacity fade in lithium-ion batteries, Journal of Power Sources 113 (1) (2003) $72-80$. 
[8] P. Ramadass, B. Haran, R. White, B. N. Popov, Mathematical modeling of the capacity fade of li-ion cells, Journal of Power Sources 123 (2) (2003) $230-240$.

[9] S. Santhanagopalan, Q. Guo, P. Ramadass, R. E. White, Review of models for predicting the cycling performance of lithium ion batteries, Journal of Power Sources 156 (2) (2006) 620-628.

[10] T. Yoshida, M. Takahashi, S. Morikawa, C. Ihara, H. Katsukawa, T. Shiratsuchi, J.-i. Yamaki, Degradation mechanism and life prediction of lithium-ion batteries, Journal of The Electrochemical Society 153 (3) (2006) A576-A582.

[11] M. Safari, M. Morcrette, A. Teyssot, C. Delacourt, Life-prediction methods for lithium-ion batteries derived from a fatigue approach: I. introduction: Capacity-loss prediction based on damage accumulation, Journal of The Electrochemical Society 157 (6) (2010) A713-A720.

[12] M. Safari, M. Morcrette, A. Teyssot, C. Delacourt, Life prediction methods for lithium-ion batteries derived from a fatigue approach: Ii. capacity-loss prediction of batteries subjected to complex current profiles, Journal of The Electrochemical Society 157 (7) (2010) A892-A898.

[13] J. Marcicki, A. Bartlett, M. Canova, A. T. Conlisk, G. Rizzoni, Y. Guezennec, X. G. Yang, T. Miller, Characterization of cycle-life aging in automotive lithium-ion pouch cells, in: Meeting Abstracts, no. 10, The Electrochemical Society, 2012, pp. 1090-1090.

[14] F. Todeschini, S. Onori, G. Rizzoni, An experimentally validated capacity degradation model for li-ion batteries in phevs application, in: 
8th IFAC Symposium on Fault Detection, Supervision and Safety of Technical Processes, IFAC, 2012.

[15] K. Goebel, B. Saha, A. Saxena, J. Celaya, J. Christophersen, Prognostics in battery health management, Instrumentation Measurement Magazine, IEEE 11 (4) (2008) $33-40$.

[16] L. Serrao, S. Onori, A. Sciarretta, Y. Guezennec, G. Rizzoni, Optimal energy management of hybrid electric vehicles including battery aging, in: American Control Conference (ACC), 2011, 2011, pp. 2125-2130.

[17] S. Ebbesen, P. Elbert, L. Guzzella, Battery state-of-health perceptive energy management for hybrid electric vehicles, Vehicular Technology, IEEE Transactions on 61 (7) (2012) 2893-2900.

[18] A. Cordoba-Arenas, S. Onori, R. Giorgio, G. Fan, Aging propagation in advanced battery systems: Preliminary results, in: IFAC Symposium Advances in Automotive Control, Japan, September, 2013.

[19] J. W. Fergus, Recent developments in cathode materials for lithium ion batteries, Journal of Power Sources 195 (4) (2010) 939-954.

[20] P. Albertus, J. Christensen, J. Newman, Experiments on and modeling of positive electrodes with multiple active materials for lithium-ion batteries, Journal of The Electrochemical Society 156 (7) (2009) A606A618.

[21] K.-W. Nam, W.-S. Yoon, H. Shin, K. Y. Chung, S. Choi, X.-Q. Yang, In situ x-ray diffraction studies of mixed $l i m n_{2} O_{4}-l i n i_{1 / 3} c o_{1 / 3} m n_{1 / 3} O_{2}$ composite cathode in li-ion cells during charge-discharge cycling, Journal of Power Sources 192 (2) (2009) 652-659. 
[22] M. Dubarry, C. Truchot, M. Cugnet, B. Y. Liaw, K. Gering, S. Sazhin, D. Jamison, C. Michelbacher, Evaluation of commercial lithium-ion cells based on composite positive electrode for plug-in hybrid electric vehicle applications. part i: Initial characterizations, Journal of Power Sources 196 (23) (2011) 10328-10335.

[23] Z. F. Ma, X. Q. Yang, X. Z. Liao, X. Sun, J. McBreen, Electrochemical evaluation of composite cathodes base on blends of limn2o4 and lini0.8co0.2o2, Electrochemistry Communications 3 (8) (2001) 425-428.

[24] M. Broussely, S. Herreyre, P. Biensan, P. Kasztejna, K. Nechev, R. Staniewicz, Aging mechanism in li ion cells and calendar life predictions, Journal of Power Sources 97-98 (0) (2001) $13-21$.

[25] M. Broussely, P. Biensan, F. Bonhomme, P. Blanchard, S. Herreyre, K. Nechev, R. Staniewicz, Main aging mechanisms in li ion batteries, Journal of Power Sources 146 (1-2) (2005) 90 - 96.

[26] I. Bloom, B. Cole, J. Sohn, S. Jones, E. Polzin, V. Battaglia, G. Henriksen, C. Motloch, R. Richardson, T. Unkelhaeuser, D. Ingersoll, H. Case, An accelerated calendar and cycle life study of li-ion cells, Journal of Power Sources 101 (2) (2001) 238-247.

[27] I. Bloom, S. A. Jones, E. G. Polzin, V. S. Battaglia, G. L. Henriksen, C. G. Motloch, R. B. Wright, R. G. Jungst, H. L. Case, D. H. Doughty, Mechanisms of impedance rise in high-power, lithium-ion cells, Journal of Power Sources 111 (1) (2002) 152-159.

[28] R. Wright, C. Motloch, J. Belt, J. Christophersen, C. Ho, R. Richardson, I. Bloom, S. Jones, V. Battaglia, G. Henriksen, T. Unkelhaeuser, 
D. Ingersoll, H. Case, S. Rogers, R. Sutula, Calendar- and cyclelife studies of advanced technology development program generation 1 lithium-ion batteries, Journal of Power Sources 110 (2) (2002) 445-470.

[29] R. P. Ramasamy, R. E. White, B. N. Popov, Calendar life performance of pouch lithium-ion cells, Journal of Power Sources 141 (2) (2005) 298 -306 .

[30] B. Y. Liaw, R. G. Jungst, G. Nagasubramanian, H. L. Case, D. H. Doughty, Modeling capacity fade in lithium-ion cells, Journal of Power Sources 140 (1) (2005) 157 - 161. doi:10.1016/j.jpowsour.2004.08.017.

[31] M. Dubarry, V. Svoboda, R. Hwu, B. Y. Liaw, Capacity and power fading mechanism identification from a commercial cell evaluation, Journal of Power Sources 165 (2) (2007) 566-572.

[32] W. Prochazka, G. Pregartner, M. Cifrain, Design-of-experiment and statistical modeling of a large scale aging experiment for two popular lithium ion cell chemistries, Journal of The Electrochemical Society 160 (8) (2013) A1039-A1051.

[33] I. Bloom, L. K. Walker, J. K. Basco, D. P. Abraham, J. P. Christophersen, C. D. Ho, Differential voltage analyses of high-power lithiumion cells. 4. cells containing nmc, Journal of Power Sources 195 (3) (2010) $877-882$.

[34] M. Ecker, J. B. Gerschler, J. Vogel, S. Käbitz, F. Hust, P. Dechent, D. U. Sauer, Development of a lifetime prediction model for lithiumion batteries based on extended accelerated aging test data, Journal of Power Sources 215 (0) (2012) 248 - 257. 
[35] S. Käbitz, J. B. Gerschler, M. Ecker, Y. Yurdagel, B. Emmermacher, D. André, T. Mitsch, D. U. Sauer, Cycle and calendar life study of a graphite $\operatorname{lini}_{1 / 3} m n_{1 / 3} \mathrm{CO}_{1 / 3} \mathrm{O}_{2}$ li-ion high energy system. part a: Full cell characterization, Journal of Power Sources (0) -.

[36] S. B. Peterson, J. Apt, J. Whitacre, Lithium-ion battery cell degradation resulting from realistic vehicle and vehicle-to-grid utilization, Journal of Power Sources 195 (8) (2010) 2385 - 2392.

[37] S. S. Zhang, The effect of the charging protocol on the cycle life of a li-ion battery, Journal of Power Sources 161 (2) (2006) 1385 - 1391.

[38] M. Uno, K. Tanaka, Influence of high-frequency charge -discharge cycling induced by cell voltage equalizers on the life performance of lithium-ion cells, Vehicular Technology, IEEE Transactions on 60 (4) (2011) 1505-1515.

[39] J. Belt, V. Utgikar, I. Bloom, Calendar and phev cycle life aging of highenergy, lithium-ion cells containing blended spinel and layered-oxide cathodes, Journal of Power Sources 196 (23) (2011) 10213 - 10221.

[40] K. L. Gering, S. V. Sazhin, D. K. Jamison, C. J. Michelbacher, B. Y. Liaw, M. Dubarry, M. Cugnet, Investigation of path dependence in commercial lithium-ion cells chosen for plug-in hybrid vehicle duty cycle protocols, Journal of Power Sources 196 (7) (2011) 3395 - 3403.

[41] M. Dubarry, C. Truchot, B. Y. Liaw, K. Gering, S. Sazhin, D. Jamison, C. Michelbacher, Evaluation of commercial lithium-ion cells based on composite positive electrode for plug-in hybrid electric vehicle appli- 
cations. part ii. degradation mechanism under $2 \& \#$ xa0;c cycle aging, Journal of Power Sources 196 (23) (2011) 10336-10343.

[42] L. Serrao, S. Onori, G. Rizzoni, Y. Guezennec, Model based strategy for estimation of the residual life of automotive batteries, in: 7th IFAC Symposium on Fault Detection, Supervision and Safety of Technical Processes, IFAC, 2009, pp. 923-928.

[43] G. Ning, R. E. White, B. N. Popov, A generalized cycle life model of rechargeable li-ion batteries, Electrochimica Acta 51 (10) (2006) 20122022.

[44] Y. Hu, S. Yurkovich, Y. Guezennec, B. Yurkovich, Electro-thermal battery model identification for automotive applications, Journal of Power Sources 196 (1) (2011) $449-457$.

[45] A. K. Suttman, Lithium ion battery aging experiments and algorithm development for life estimation, Master's thesis, The Ohio State University (2011).

\section{Figure Captions}

Figure 1: Schematic of SOC profile under PHEV operation: charge depleting (CD), charge sustaining (CS) and charging.

Figure 2: Charge depliting (CD) and charge sustaining (CD) power micro-cycles [1].

Figure 3: Voltage Response during the capacity characterization tests for experiment 16 . 
Figure 4: Capacity loss for: (a) temperature experiments; (b) Ratio experiments; (c) $\mathrm{SOC}_{\min }$ experiments (all conducted with a Ratio of 0). Experimental data are shown as markers, and the model, as solid curve.

Figure 5: Capacity severity factor function from Ratio experiments. Capacity severity factor points obtained form the experimental data best curve fittings are shown as markers, and the model, as solid curve (Equation 8).

Figure 6: Capacity loss for all the experiments conducted with a Ratio of 1 at $\mathrm{SOC}_{\min }=35 \%$. Experimental data are shown as markers, and the model, as solid curve.

Figure 7: Capacity severity factor function from $\mathrm{SOC}_{\min }$ experiments, all conducted witha Ratio of 0 . Capacity severity factor points obtained form the experimental data best curve fittings are shown as markers, and the model, as solid curve (Equation 9).

Figure 8: Capacity severity factor map. The experimental points are shown as markers, and the severity function, as solid surface (Equation 11).

Figure 9: Capacity loss for $\mathrm{SOC}_{\min }$ experiments, all conducted with a Ratio of 1. Experimental data are shown as markers, and the model, as solid curve (Equation 20), (a) Experiments conducted with $\mathrm{SOC}_{\min }=25 \%$, (b) Experiments conducted with $\mathrm{SOC}_{\min }=45 \%$

Figure 10: Schematic of the input current and cell voltage response during the first 100 seconds of a CD micro-duty cycle. The initial currents and voltages used for the resistance calculations are shown as square markers; the final currents and voltages as triangle markers; and the input current and voltage response as solid curves.

Figure 11: Resistance data from experiment \#16 before and after the outlier removal and filtering.

Figure 12: Resistance increase for: (a) temperature experiments; (b) 
$\mathrm{SOC}_{\min }=25 \%$ experiments, $T=30 C^{o} ;(\mathrm{c}) \mathrm{SOC}_{\min }=35 \%$ experiments,$T=$ $30 C^{o}$; (d) $\mathrm{SOC}_{\min }=45 \%$ experiments, $T=30 C^{o}$. Experimental data are shown as markers, and the model, as solid curve.

Figure 13: Resistance severity factor surface. Resistance severity factor points obtained form the experimental data best curve fittings are shown as markers, and the model, as solid surface (Equation 21).

\section{Table Captions}

Table 1: Summary of aging experiments 


\begin{tabular}{|l|l|l|l|l|l|l|}
\hline $\begin{array}{l}\text { Experiment } \\
\#\end{array}$ & $\begin{array}{l}\text { Operating } \\
\text { mode }\end{array}$ & $\begin{array}{l}\text { Ratio } \\
\left(t_{C D}: t_{C D+C S}\right)\end{array}$ & $\begin{array}{l}\mathbf{S O C}_{\text {min }} \\
{[\%]}\end{array}$ & $\begin{array}{l}\text { Charging } \\
\text { C-rate }\end{array}$ & $\begin{array}{l}\text { Temperature } \\
{\left[C^{o}\right]}\end{array}$ & $\begin{array}{l}\text { Charge } \\
\text { throughput } \\
\text { [Ah] }\end{array}$ \\
\hline 1 & & 1 & 45 & $\mathrm{C} / 3$ & 30 & 12364 \\
2 & 1 & 35 & $\mathrm{C} / 3$ & 30 & 13985 \\
3 & 1 & 25 & $\mathrm{C} / 3$ & 30 & 12713 \\
4 & & 45 & $3 \mathrm{C} / 2$ & 30 & 24361 \\
5 & & 35 & $3 \mathrm{C} / 2$ & 30 & 25353 \\
6 & Charge & 1 & 25 & $3 \mathrm{C} / 2$ & 30 & 27597 \\
7 & depleting & 1 & 45 & $5 \mathrm{C}$ & 30 & 24292 \\
8 & 1 & 35 & $5 \mathrm{C}$ & 30 & 28141 \\
9 & & 1 & 25 & $5 \mathrm{C}$ & 30 & 30704 \\
\hline 10 & & 1 & - & 30 & 17477 \\
11 & & 0 & 35 & - & 30 & 20080 \\
12 & Charge & 0 & 25 & - & 30 & 16385 \\
\hline 13 & sustaining & 0 & 35 & $3 \mathrm{C} / 2$ & 10 & 20719 \\
14 & \multirow{2}{*}{ Mixed } & $1 / 2$ & 35 & $3 \mathrm{C} / 2$ & 30 & 23087 \\
15 & $1 / 2$ & 35 & $3 \mathrm{C} / 2$ & 30 & 21316 \\
16 & & $1 / 4$ & 35 & $3 \mathrm{C} / 2$ & 45 & \\
\hline
\end{tabular}

*attained by cell at the end of the experiment 
CD power micro cycle

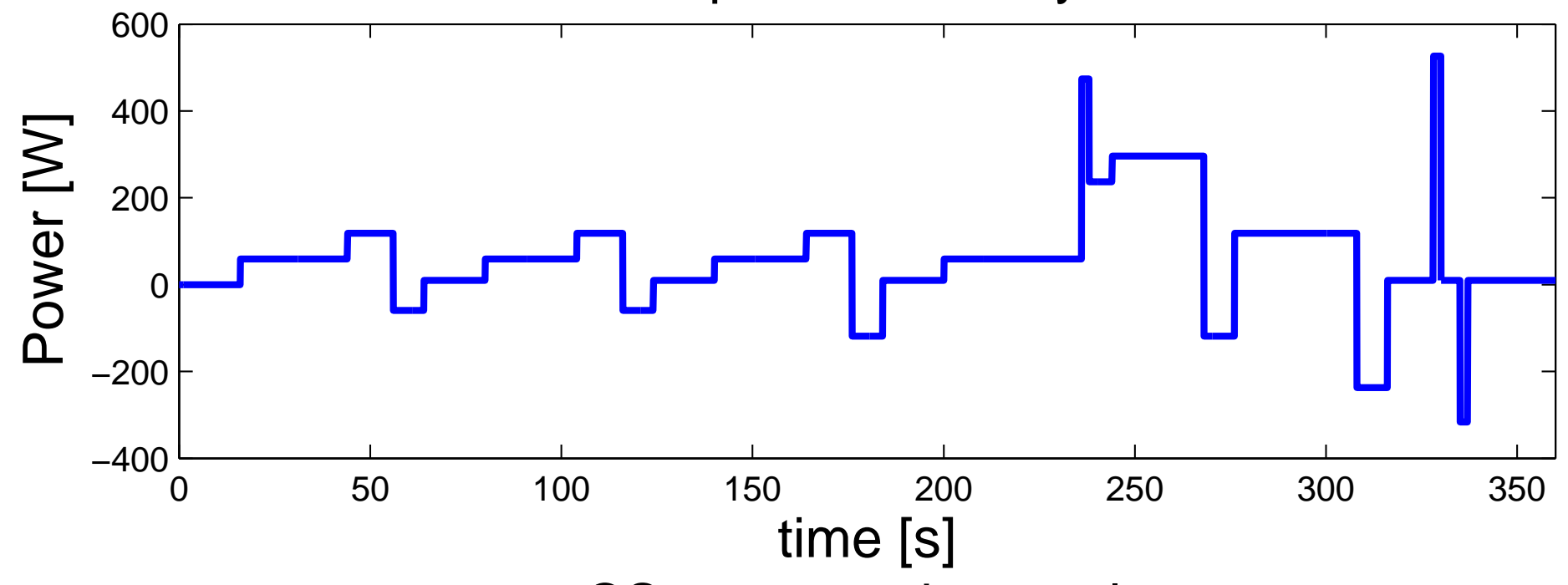

CS power micro cycle

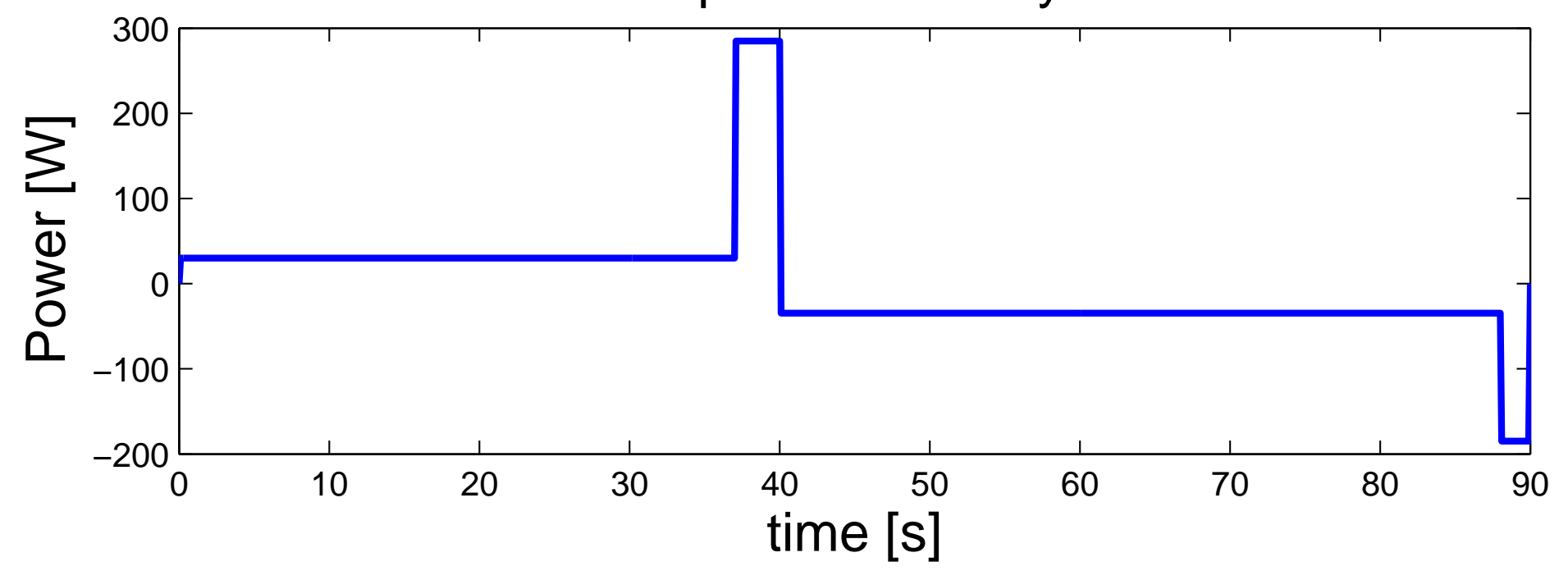




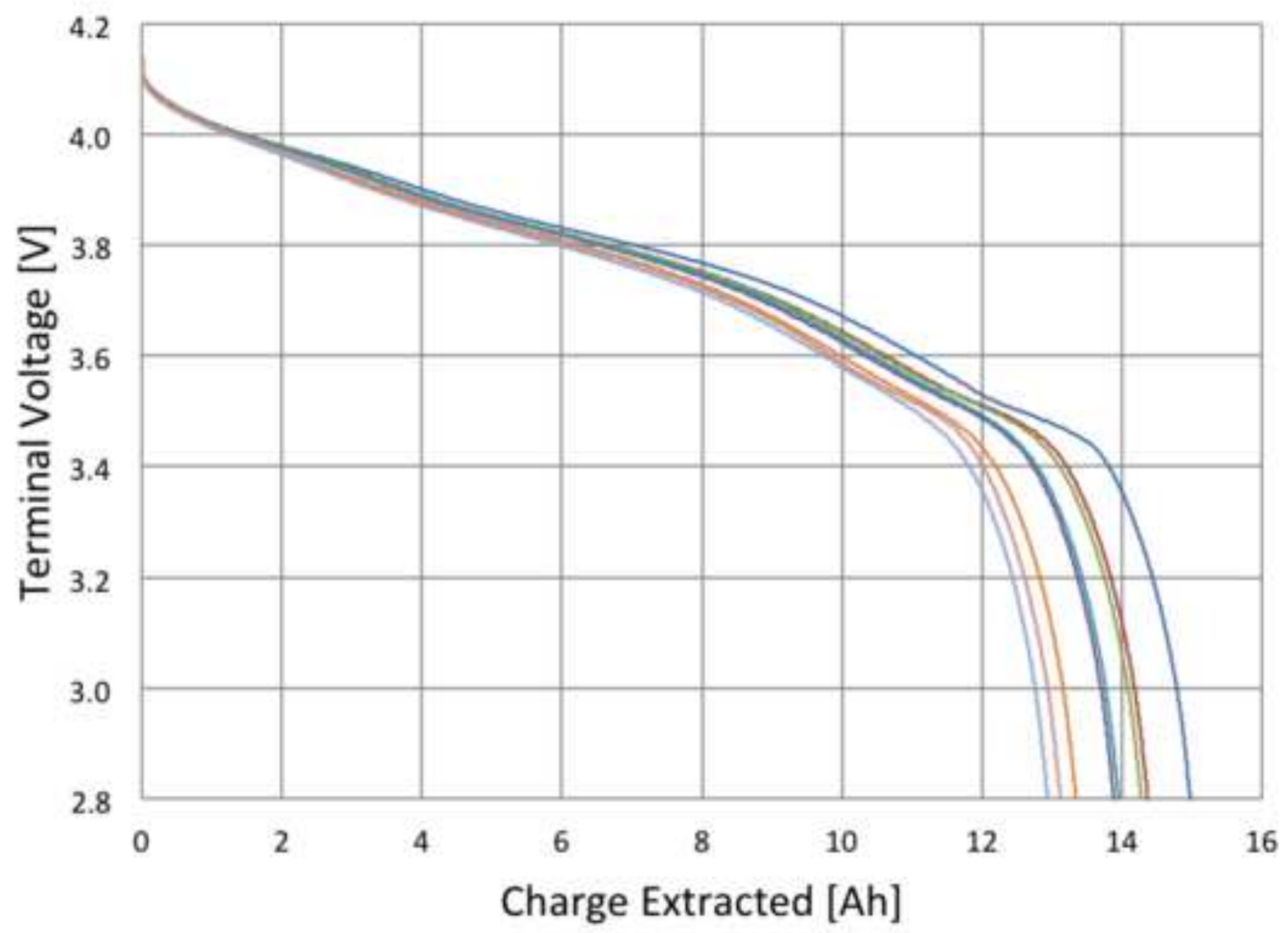

—Initial

— Test1 (3.1 kAh)

— Test2 (4.7 kAh)

- Test3 (8.5 kAh)

— Test4 (12.8 kAh)

— Test5 (17.5 kAh)

— Test6 (21.0 kAh)

— Test7 (21.3 kAh) -

Charge Extracted [Ah] 


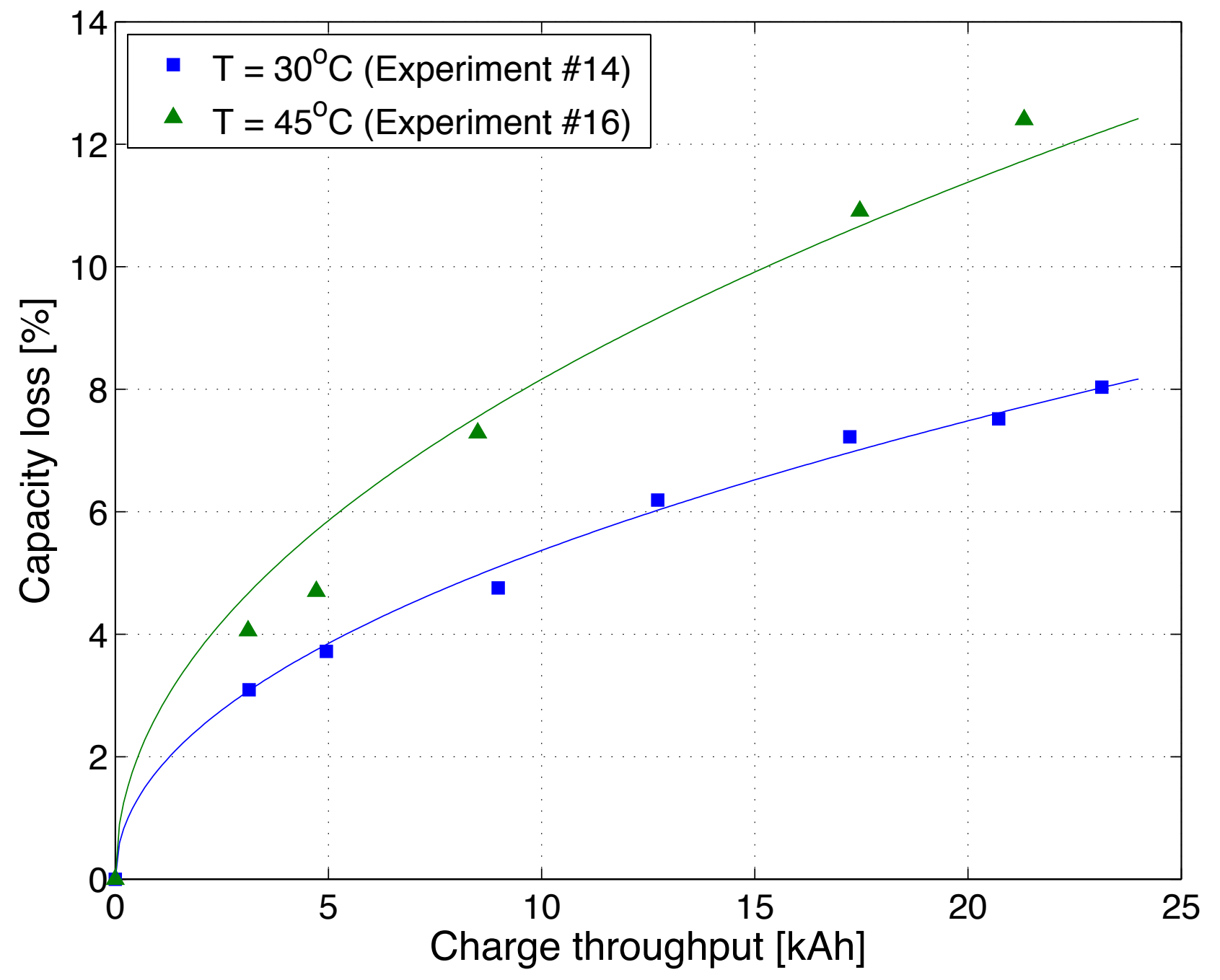

(a)

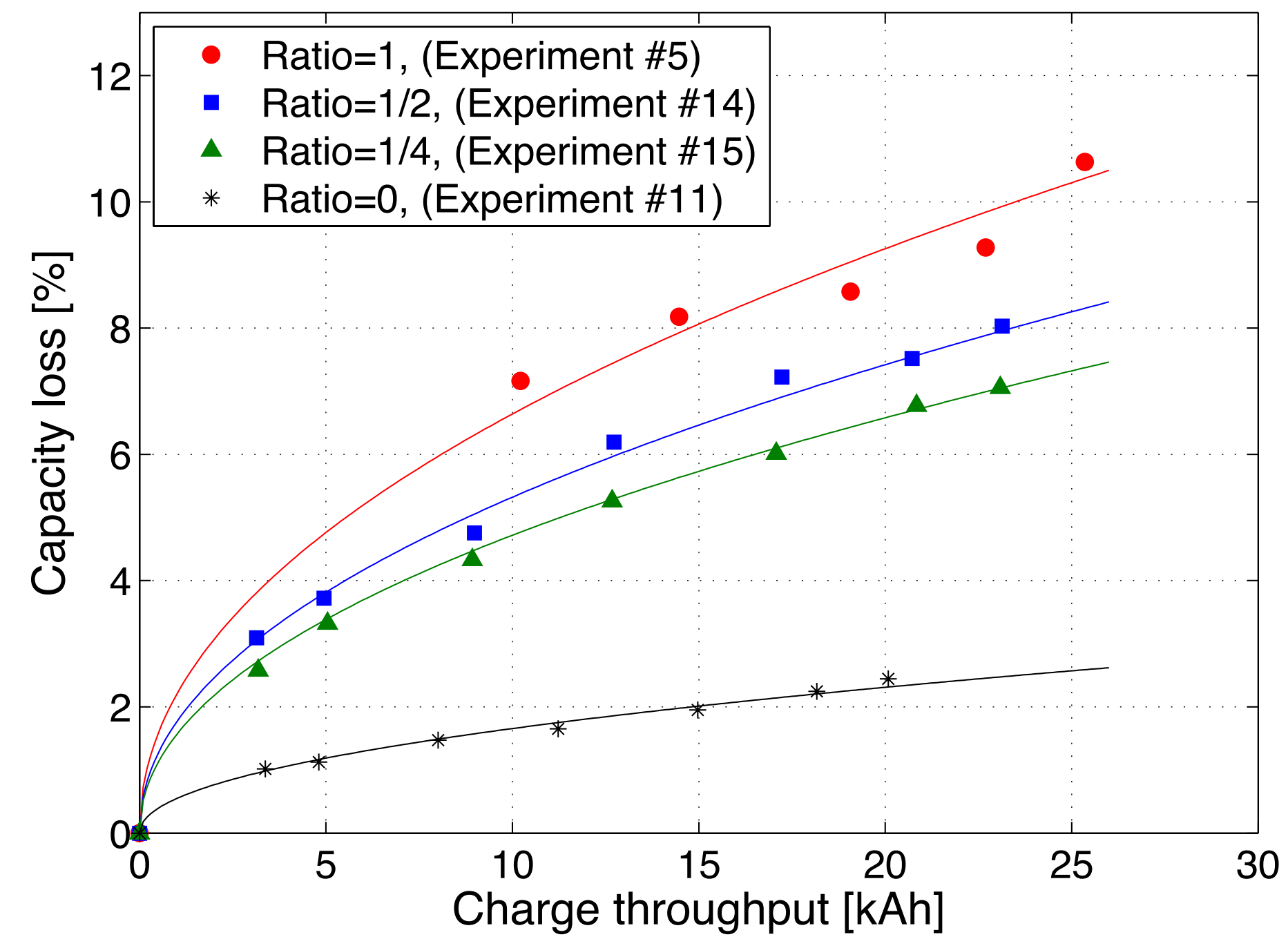

(b)

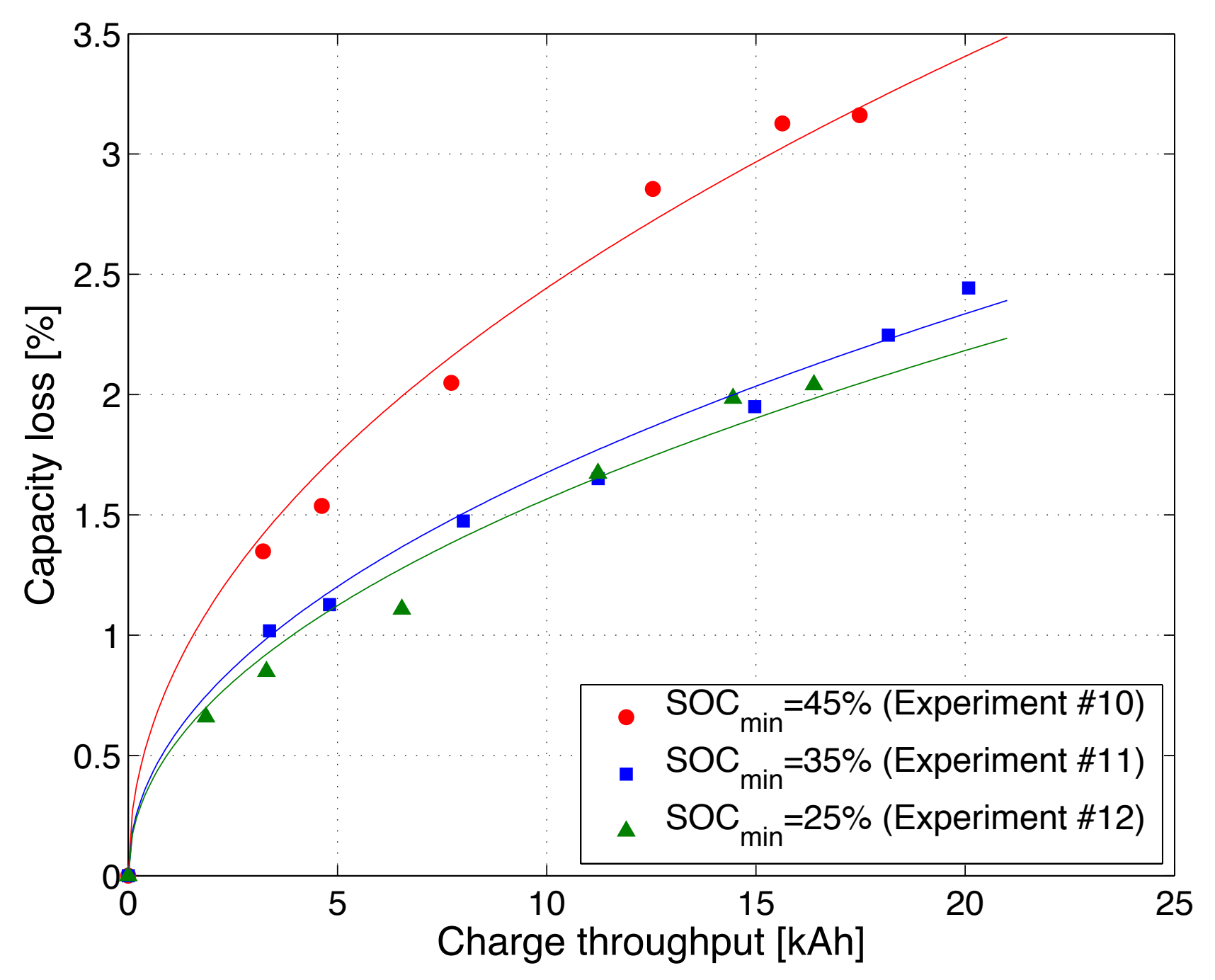

(c) 


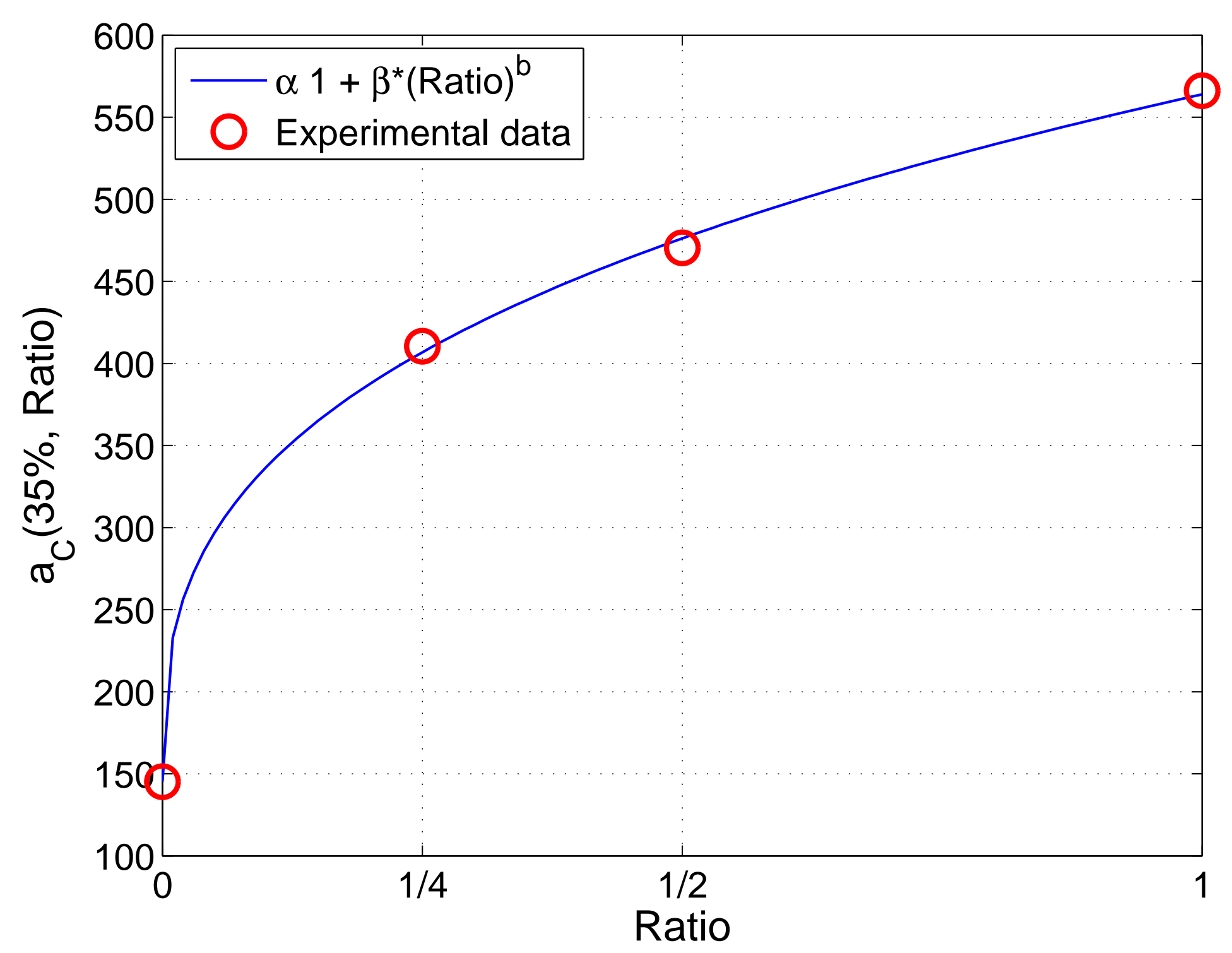

Figure 5 
Figure 6

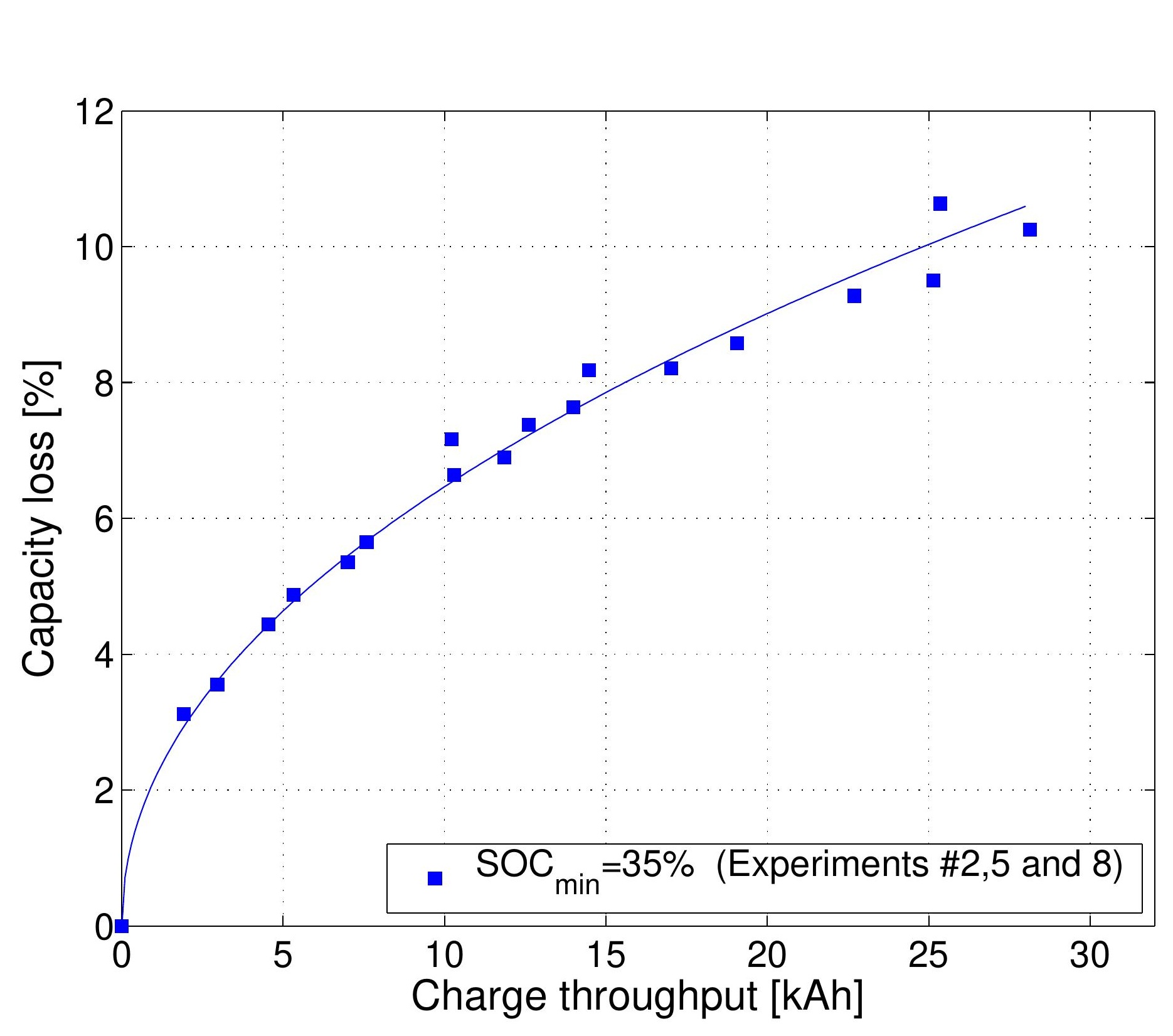

Figure 
Figure 7

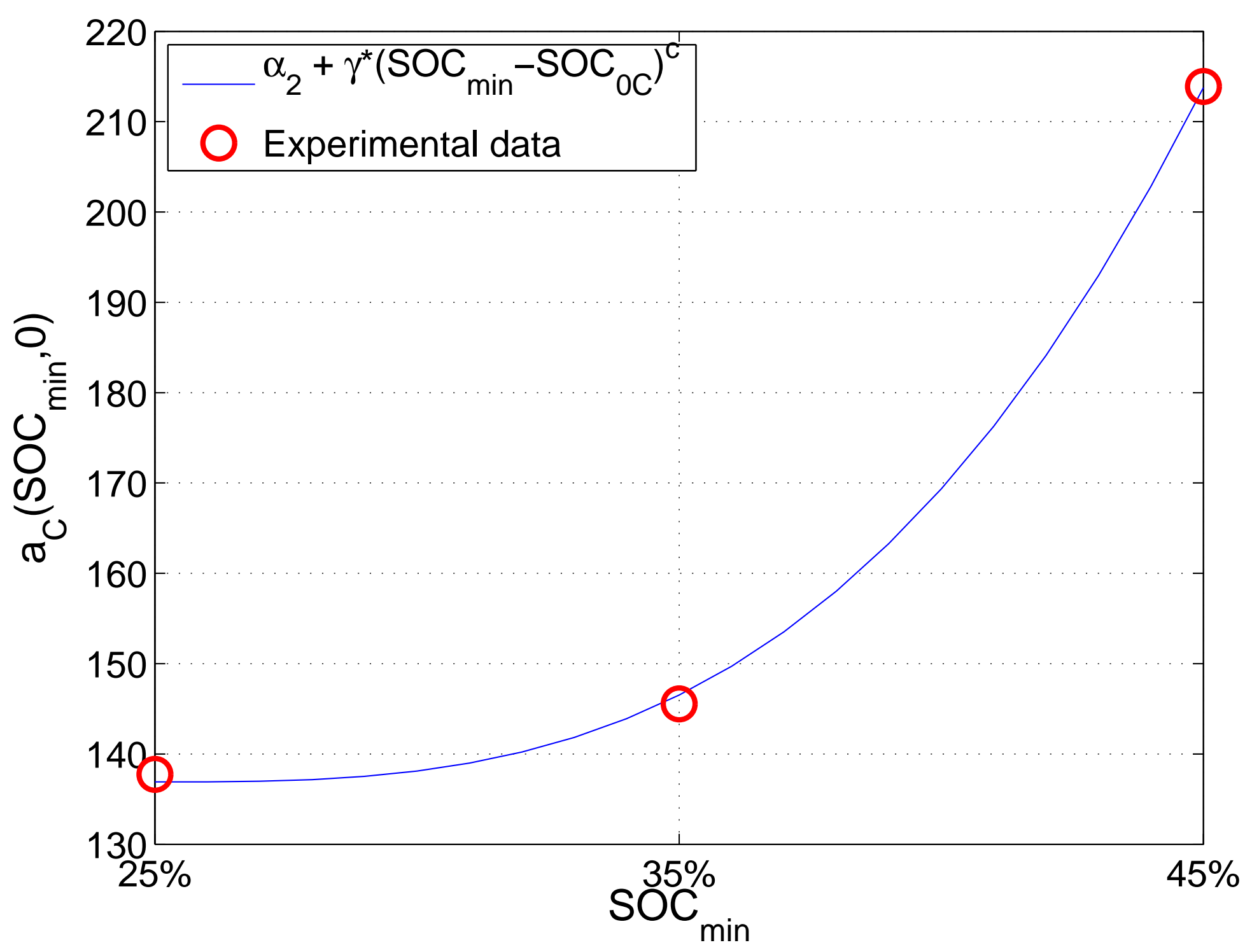




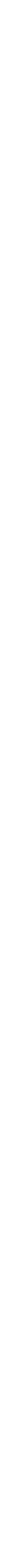

Figure 8
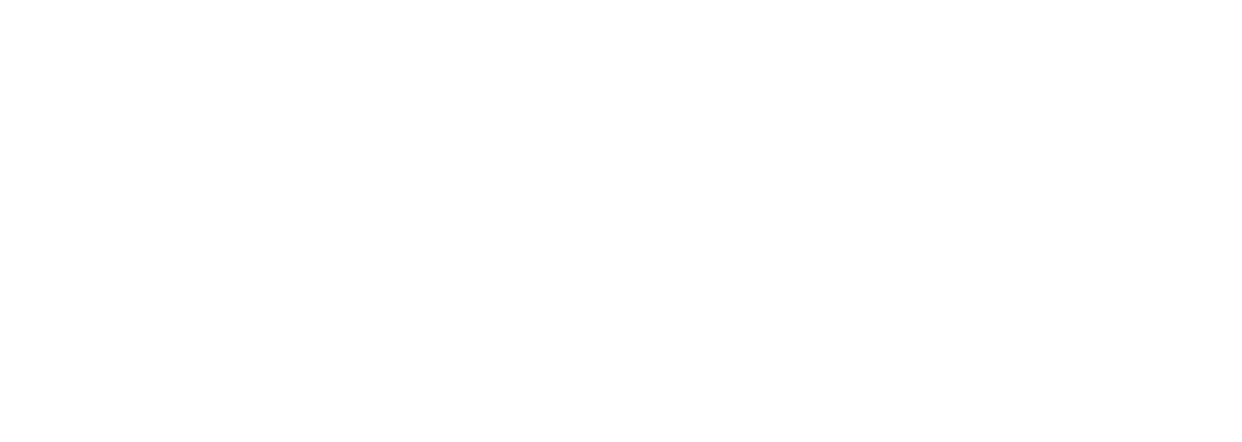
(a)

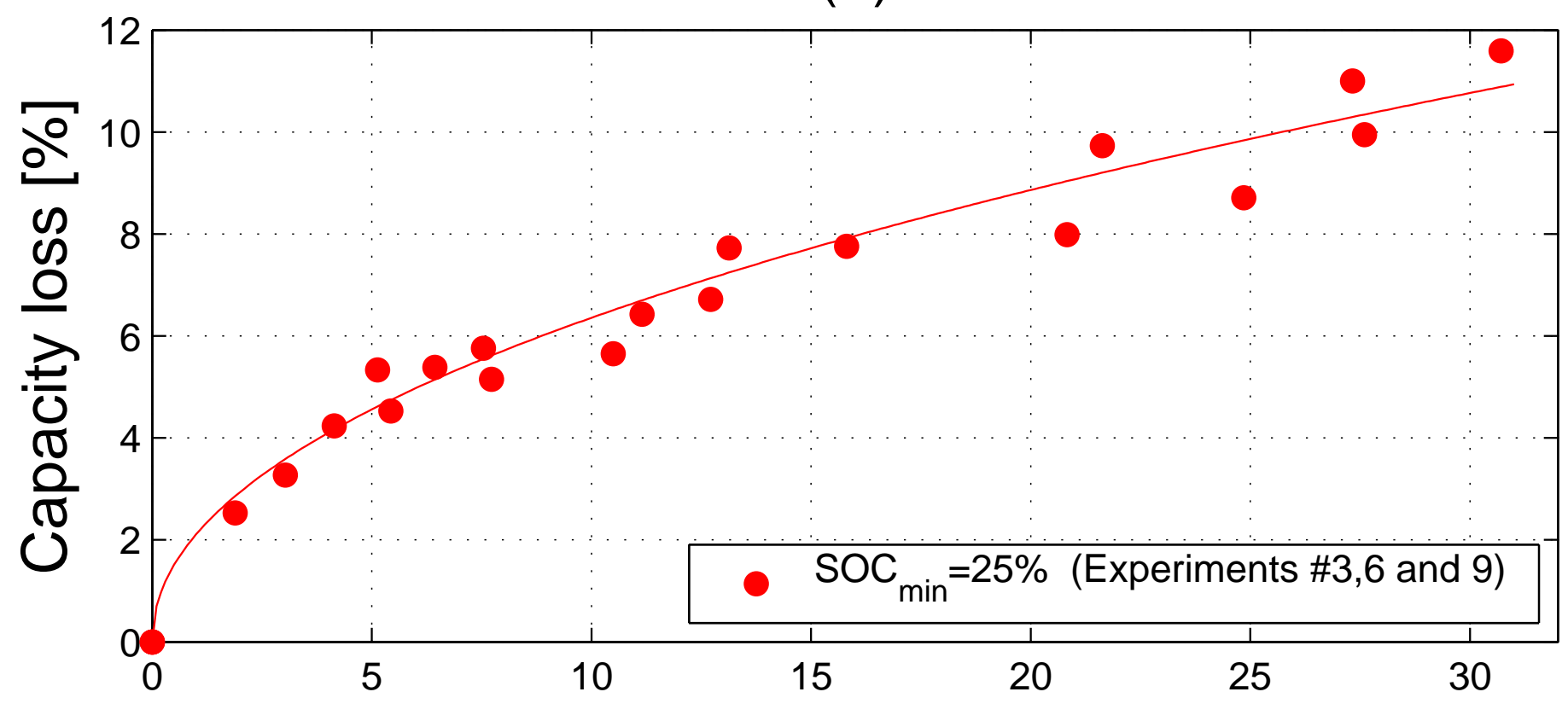

(b)

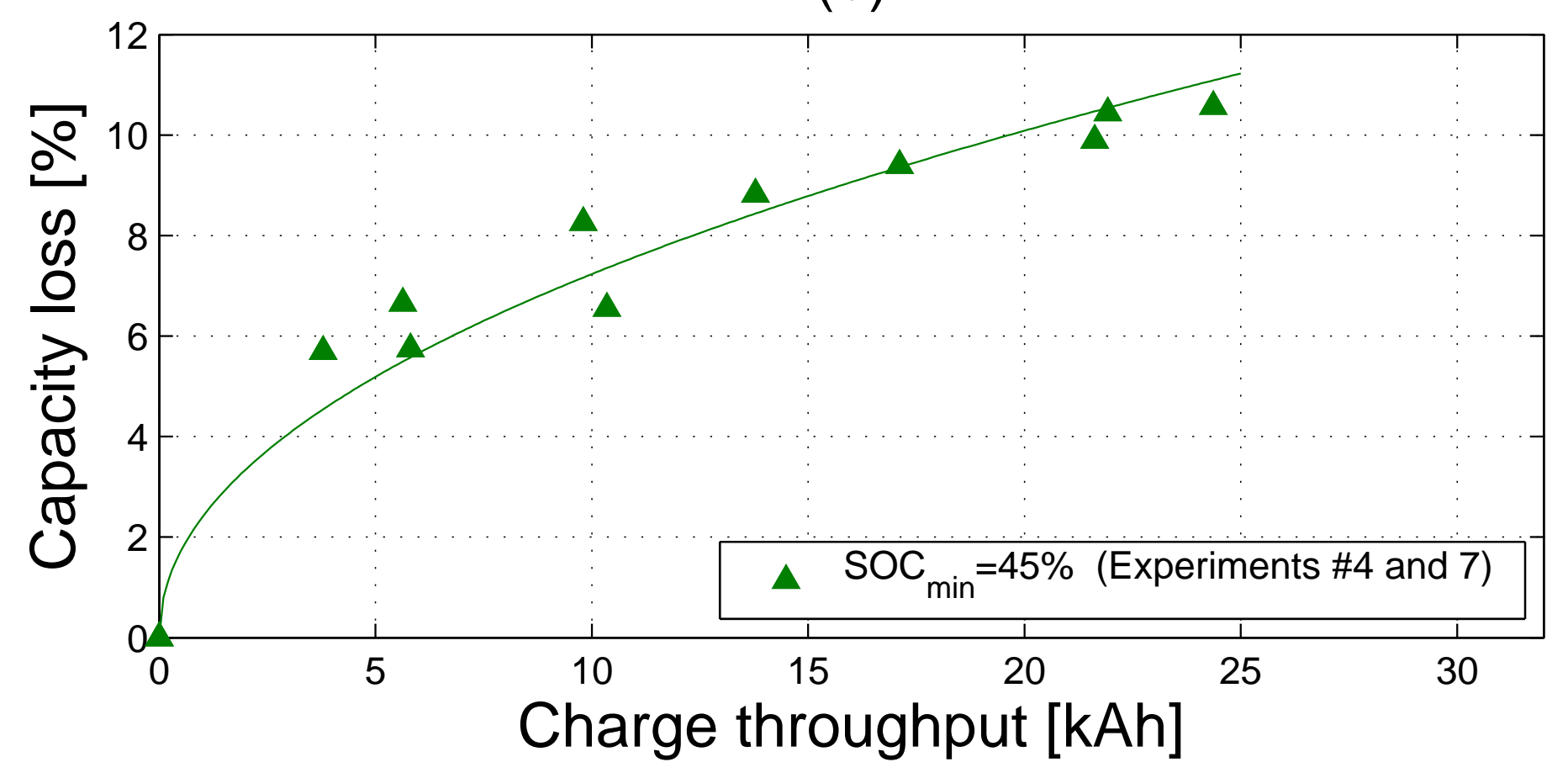



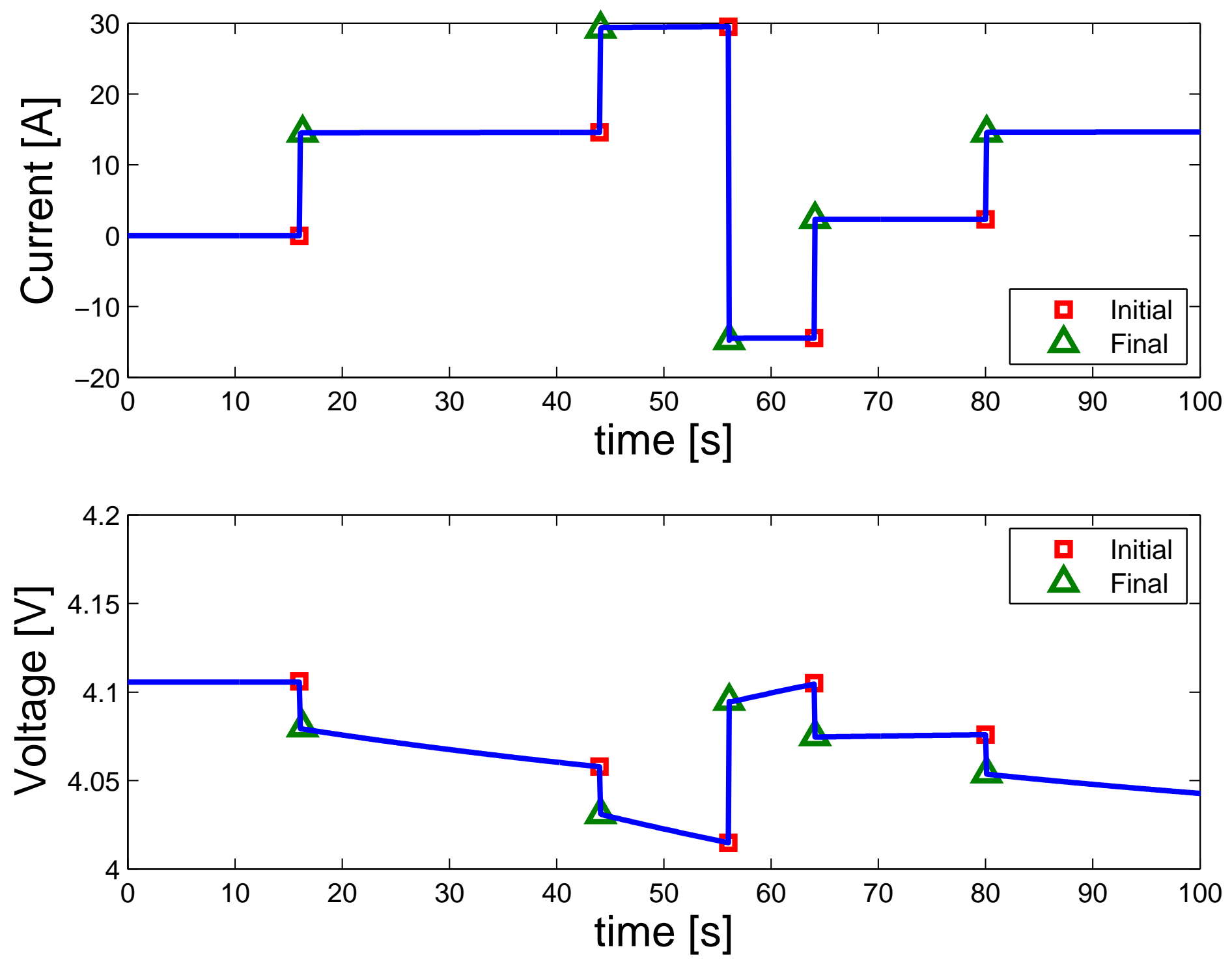


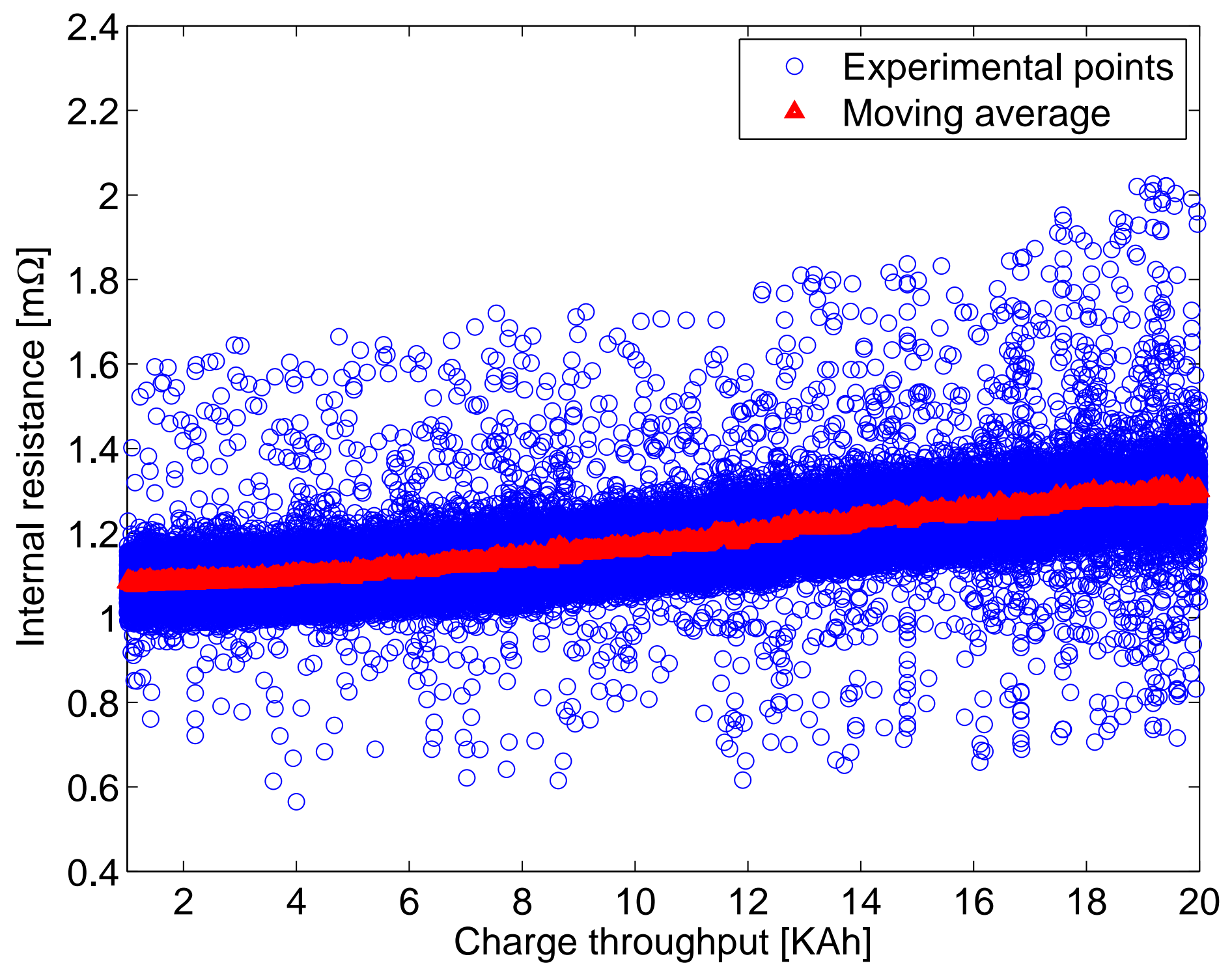




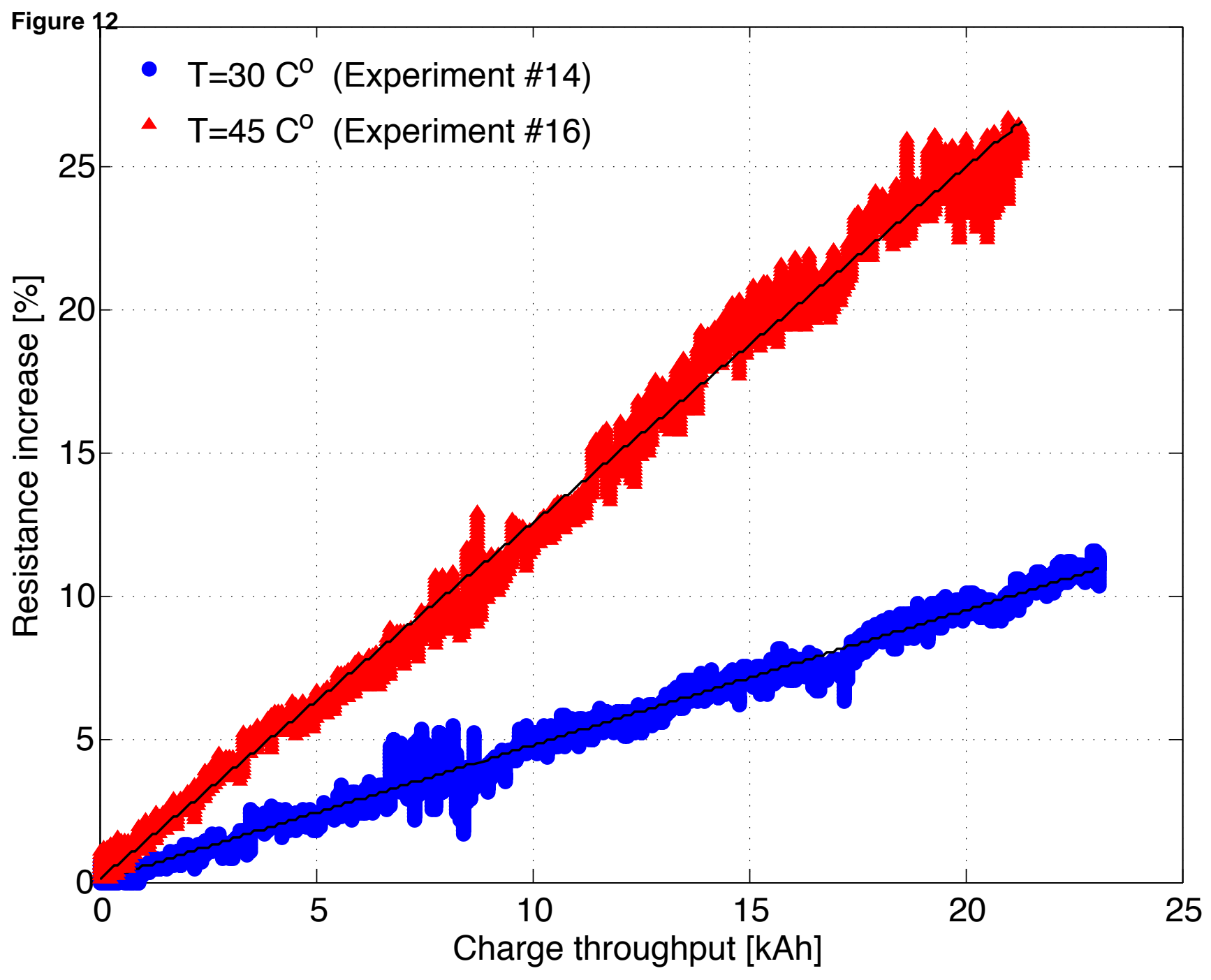

(a)

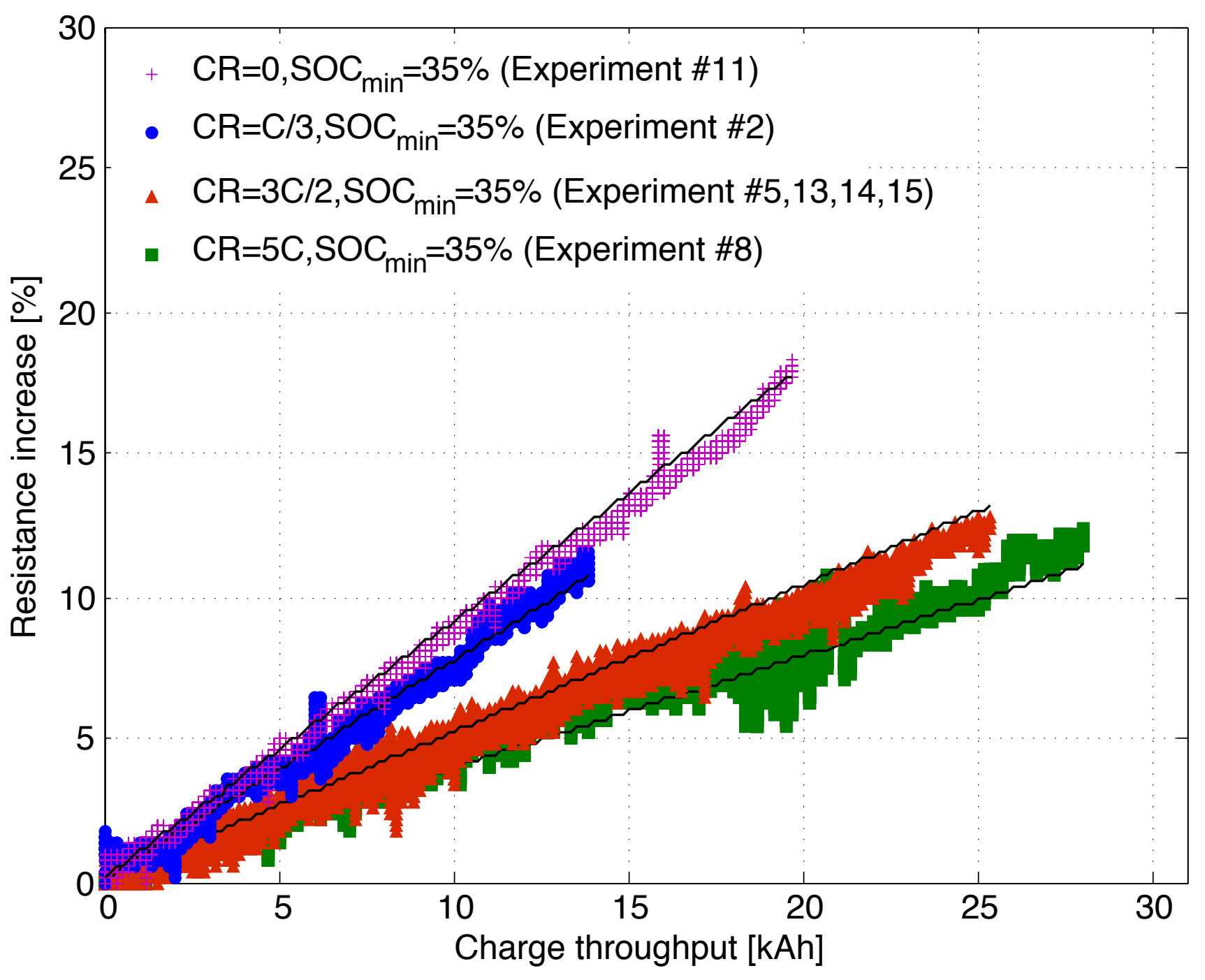

(c)

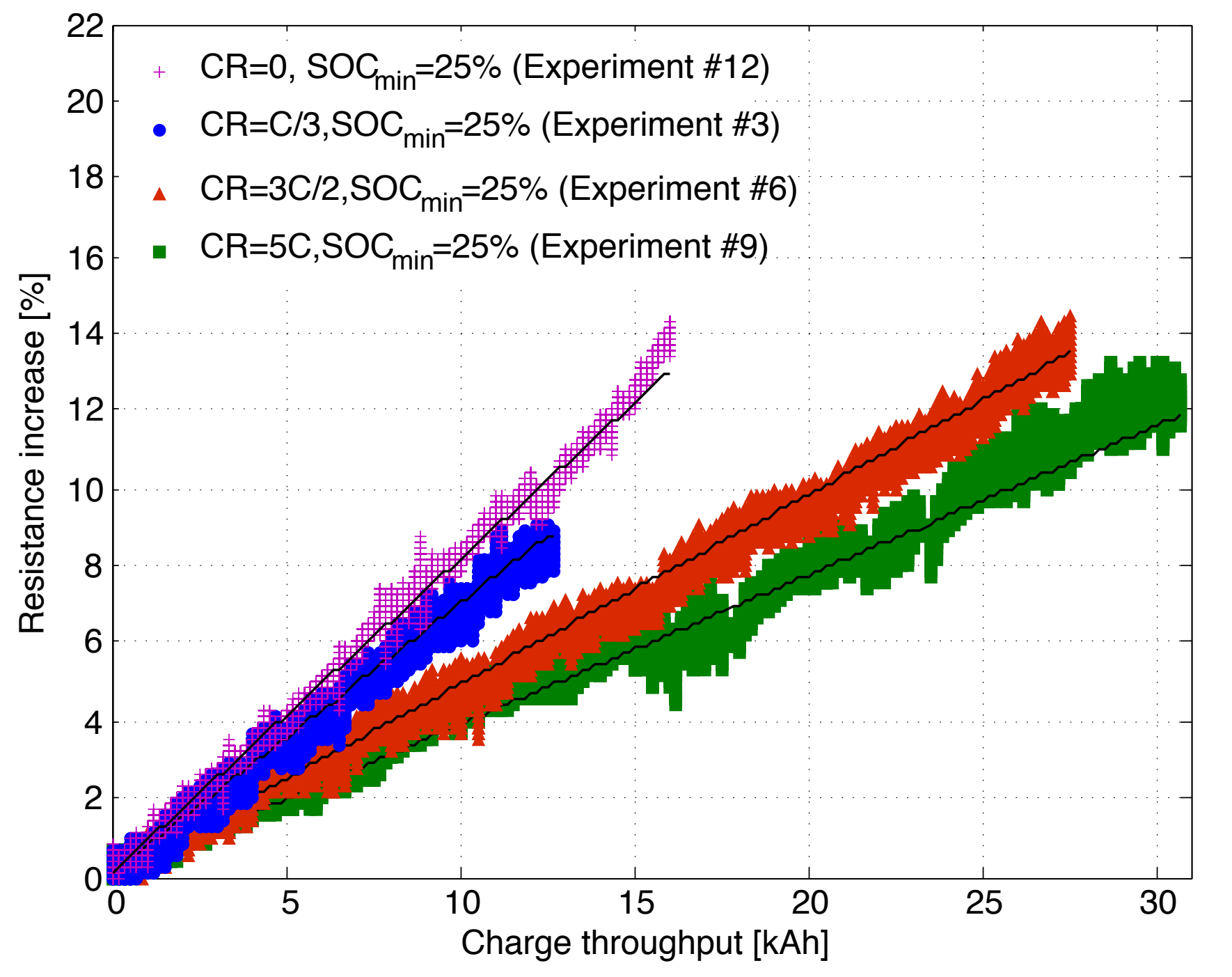

(b)

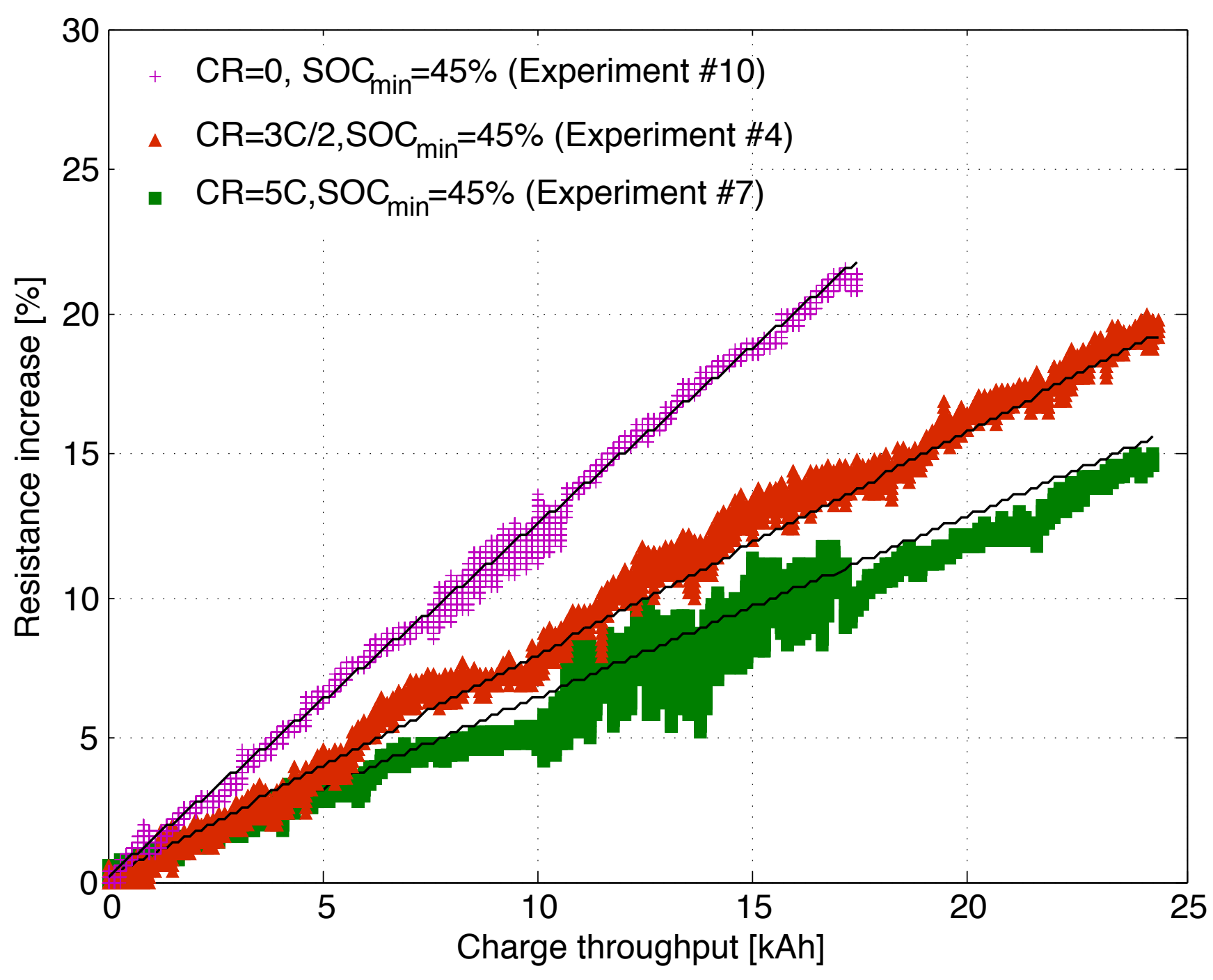

(d) 


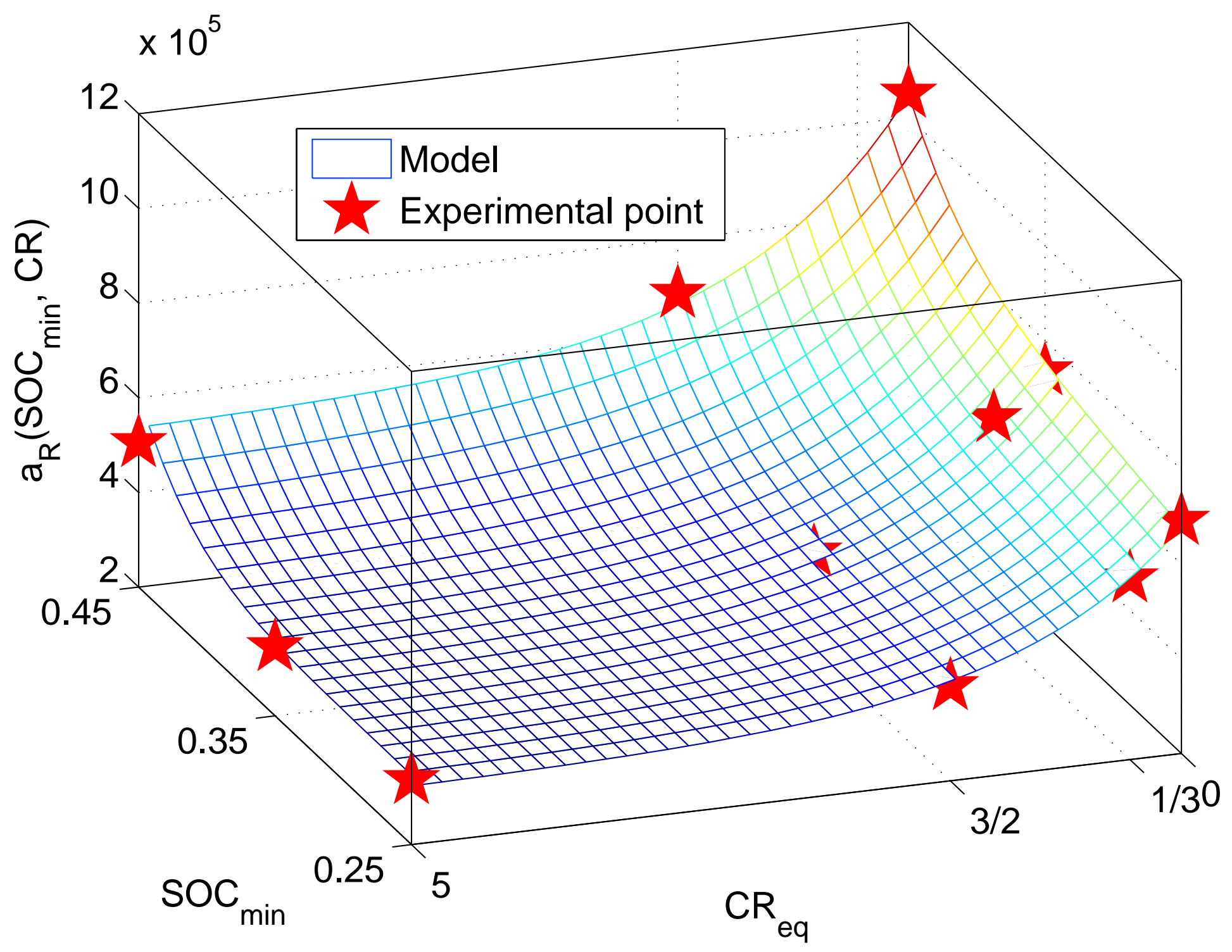

